\title{
A NOVEL FULL SCALE LABORATORY FOR YACHT ENGINEERING RESEARCH
}

\author{
F. Fossati ${ }^{1 *}$, I. Bayati ${ }^{1}$, F. Orlandini ${ }^{1}$, S. Muggiasca ${ }^{1}$, A. Vandone $^{1}$, G. Mainetti ${ }^{1}$, R. Sala ${ }^{1}$ \\ C. Bertorello" ${ }^{2}$ E. Begovic ${ }^{2}$ \\ ${ }^{\mathbf{1}}$ Department of Mechanical Engineering, Politecnico di Milano, Italy, \\ ${ }^{2}$ Department of Industrial Engineering, Marine Section, Università degli Studi di Napoli Federico II, Italy \\ *corresponding author: fabio.fossati@polimi.it
}

\begin{abstract}
The present paper presents an overview of the Lecco Innovation Hub project and in particular of the Sailing Yacht Lab project a $10 \mathrm{~m}$ length sailing yacht which aims to be a full scale measurement device in the sailing yacht research field. A description of scientific frame, measurement capabilities as well as of the principal design, building process, project management and committing are provided with some examples of preliminary collected data obtained during the first sea trials. Finally an overview of the ongoing project tasks and future project developments is provided including potential research and knowledge achievements for sailing yacht research field.
\end{abstract}

\section{INTRODUCTION}

The present paper presents an overview of the Lecco Innovation Hub project and in particular of the Sailing Yacht Lab project which aims to be a full scale measurement device in the sailing yacht research field.

Lecco Innovation Hub ( $\mathrm{LIH})$ is a dedicated nautical research and training centre at the Lecco Campus of the Politecnico di Milano university aiming to encourage the transfer of technology to and from the nautical and related sectors.

Lecco Innovation Hub consists of two basic entities:

- The Sailing Yacht Lab (SYL), a $10 \mathrm{~m}$ length sailing yacht fitted with instruments for acquiring data on the behavioural variables of the boat and her components at full scale to support a scientific approach to design and research activities related to sailing yacht design and performance

- The S.Ma.R.T. (Sustainable Marine Research and Technology) laboratory designed to support nautical industry in meeting the increasing pressing demands for innovation and sustainability. Specific lines of research are the analysis and assessment of the entire life cycle (LCA) of nautical products, design for disassembling, experimentation with new materials for construction and fitting out, ergonomics, safety and comfort on board, interior lighting and the improvement of the quality of air.

In addition to these, there are the research infrastructures present in other sites of the Politecnico di Milano, such as the Wind Tunnel - Europe's largest - on the Milan Bovisa campus [1].

Aim of this paper is to provide an overview of the Sailing Yacht Lab project: a brief summary of the origin and early evolution of the vessel's design will be given, along with a description of principal design and performance criteria.

Design, building process, project management and committing will be described in the following; the measurement capabilities and data acquisition procedure will be described in details.

The project is still in progress; in order to put into perspective research the capabilities provided by this new available tool some examples of preliminary collected data obtained during the first sea trials are reported and discussed.

Finally an overview of the ongoing project tasks and future project developments is provided including potential research and knowledge achievements for sailing yacht research field.

\section{FULL SCALE TESTING}

The ability to predict the maximum potential performance of a racing sailboat is a strong asset yet demanding verification of both experimental results and numerical derived data.

First methodical approaches for calculating yacht performance came not before the Thirties as demonstrated by the GIMCRACK case when Olin Stephens and the Davidson Laboratory at Stevens Institute developed a full experimental program combining full scale sailing testing and tank tests on scale model with the intention of determining sail coefficients and predicting performance of sailing vessels.

The estimation of a sailboat's potential speed based on its design alone began in the 1930's with sea trials of GIMCRACK a 34'-6" LOA, 23' LWL low- freeboard day-sailer designed by Sparkman \&Stephens.

Since 1936 when Gimcrack sailing performances were measured at full scale, the most of such tests have been performed in the frame of America's Cup boats technical development aimed at comparative analysis. 
Olin Stephens and the Davidson Laboratory at Stevens Institute successfully used Gimcrack to correlate scale model results with full-scale sailing testing, deriving the longitudinal driving force, aerodynamic side force and heeling moment. The correlation constants between model and full-scale performances derived by these studies became known as the Gimcrack Coefficients [2]. The Gimcrack Coefficients were the first known comparison of this type, proving to be a significant breakthrough in the science of sailing yacht performance prediction.

The scientific data currently available to designers and builders derive from studies based on numerical or experimental data generally obtained from scale models, prototypes or material samples analysed in artificial environments, such as wind tunnels, towing tanks or test benches.

With particular reference to sail aerodynamics, the methods currently used to attempt to characterise a sail plan are tests either in wind tunnels on scale models or on full size boats and the use of computational fluid dynamics.

At present numerical methods provide sound results for upwind and close reaching sailing but are still under development for downwind sail design. This is because the numerical techniques developed for the aeronautical sector can be applied to sails used for upwind sailing because these behave like thin airfoils affected only to a limited flow separation, while it is much more complex to solve the flow pattern that develops around a spinnaker or gennaker where the significant amount of curvature leads to large areas of flow separation. In addition downwind sail aerodynamics is actually affected by the aeroelastic mechanism: the "flying" shape of an offwind sail under real sailing conditions is determined by the pressure distribution acting upon the sail, which are not depending only on wind strength and direction but also from structural properties and sails trim controls acting upon the edges and corners of the sail as well as on forces applied to the rig and sail. All of these factors contribute to the virtually infinite number of flying shapes over the range that a particular sail can achieve under actual sailing conditions and differently from the upwind sails this is particularly true for downwind sails, as spinnakers, gennakers and MPS because of the light weight of the construction materials and their relatively unconstrained nature ([3], [4], [5]).

The insufficient reliability of numerical tools and a better understanding of the general relation between model tests, numerical simulations (e.g. CFD methods) and full scale data have encouraged the ambition of collecting data at fullscale, in real sailing conditions.

A direct measurement system of actual sail forces and moments in sailing conditions was initially developed by Milgram et al. [6]: this system was based on a 35 foot boat containing an internal frame connected to the hull by means of load cells. The high effectiveness and potential of the sailing dynamometer have been definitely demonstrated by the more recent experiences of Fujin and DYNA projects developed at Kanazawa Institute of Technology [7] and Berlin TU [8]. In particular the work achieved by Masuyama et al. with Fujin boat was mainly aimed at investigating the upwind sail aerodynamics in steady state conditions and the obtained results were compared with the numerical calculations using the measured sail shapes as input data. Then the aerodynamic force variation during tacking was measured and a new manoeuvre simulation model was proposed [9].

On the other side DYNA project deals extensively also with hydrodynamics aspects in terms of interaction hull-keelrudder aimed at appendages optimization.

Another interesting experience involving full scale testing is given in [10] where a project focused on the actual loads acting on a sailing yacht such as slamming, rudder, chainplate and grounding loads from the keel is reported. An "half tonner" (a racing yacht about 39' LOA) was built with the starboard side of sandwich construction and the port side of single skin construction with two longitudinal stringers in addition to the bottom structure and equipped with pressure and strain gauges. Statistical data were gathered during 2700 nautical miles of sailing during which 300 hours was the measuring time giving new and valuable information.

Due to the limited craft dimensions, a series of the International Moth class full scale tow tests have been recently performed [11] to characterize some of the major parameters impacting the performance of a foiling Moth providing a sound technical basis for further performance improvements of these boats.

With reference to the experimental validation of aero-elastic model in [12], the full scale testing activities performed on a J80 sailboat are described: a dedicated instrumentation is developed to measure the loads at shrouds and at tension points of the sails, the yacht motion, the sails flying shape and the navigation data providing useful data for the validation of the fluid-structure interaction model described in [13].

At present, the pressure distribution measurements on the surface of full scale sails is under investigation by several research groups: this in fact represents the key point for the role of full scale tests as a bridge between model tests and numerical methods.

In [14], [15], [16],[17] several pressure measurements are reported; the comparison with measured data by wind tunnel tests shows very interesting differences in the pressure distribution between full scale and model scale. Pressure measurements are also combined with sail shape measurements at full-scale aiming to evaluate the forces and attempting interesting investigations into steady and unsteady sail aerodynamics [18].

Within this frame the ambition of the Sailing Yacht Lab is to allow pressure and sail shape measurements in addition to the forces measurements providing more precise information thanks to the dynamometer including boat dynamics. Furthermore some evolution with reference to the pressure and sail shapes measurements systems can be provided. 


\section{THE SAILING YACHT LAB DYNAMOMETER SYSTEM}

The Sailing Yacht Lab (figure 1) is designed to operate as a dynamometric balance and was strongly inspired and encouraged by the previous experiences developed at MIT [6], at Kanazawa Institute of Technology [7] and Berlin TU [8].

The heart of the system is a 5083 aluminium alloy frame inside the hull that allows the entire rig and sail plan to be connected to a set of load cells to measure the overall forces and moments transmitted by sails and rig to the hull.

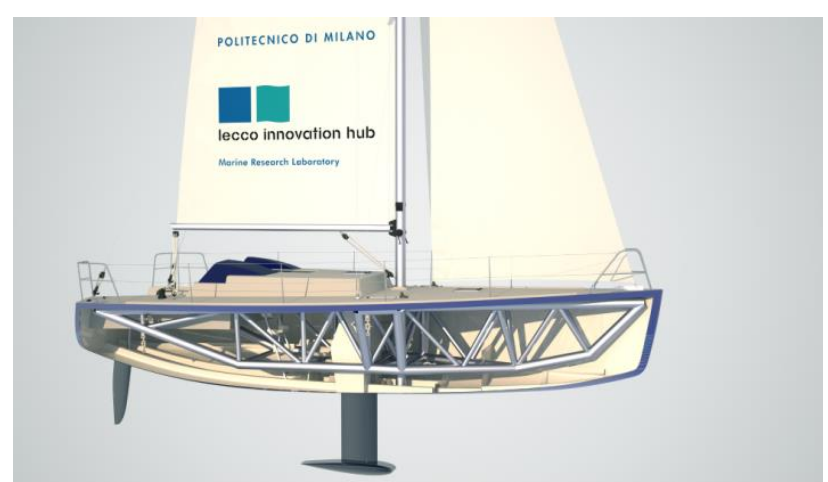

Figure 1 Sailing Yacht Lab concept

Figure 2 shows the general arrangement of the six load cells which keep the frame in isostatic constrained configuration with respect to the hull.

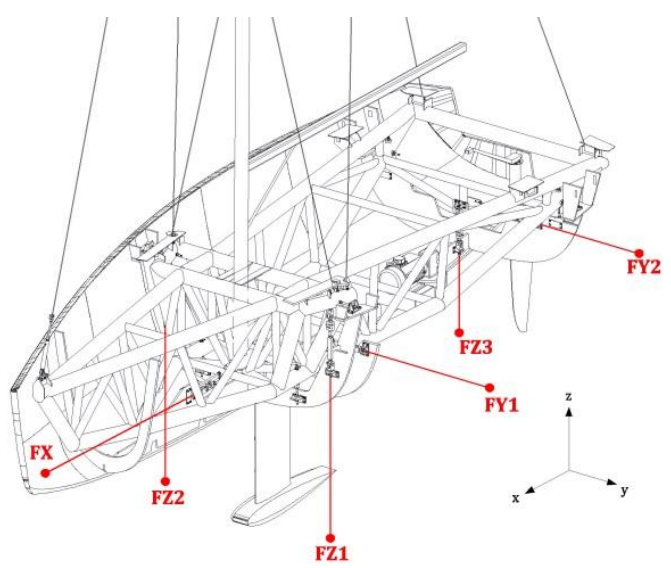

Figure 2: Load cells arrangement

With respect to the shown reference system, the 6 load cells are set as follows: one load cell along $\mathrm{x}$ direction (FX), two along y direction (FY1, FY2) and three along z direction (FZ1, FZ2, FZ3). The idea behind the choice of their position is to be as near as possible to the highest loads along the respective directions, so that e.g. FX cell is placed near the maststep connecting the hull to the central part of the frame. In addition an important criterion of the positioning of the cells was their accessibility during maintenance operation.

Maximum loads of the adopted cells are respectively $20 \mathrm{kN}$ for the FX, FY1, FY2, FZ3 and $50 \mathrm{kN}$ for the FZ1 and FZ2. The connection of the load cells to the frame and to the hull fixes any possible axial misalignment allowing each monoaxial load cell to measure no different forces than the axial ones (figure 3).

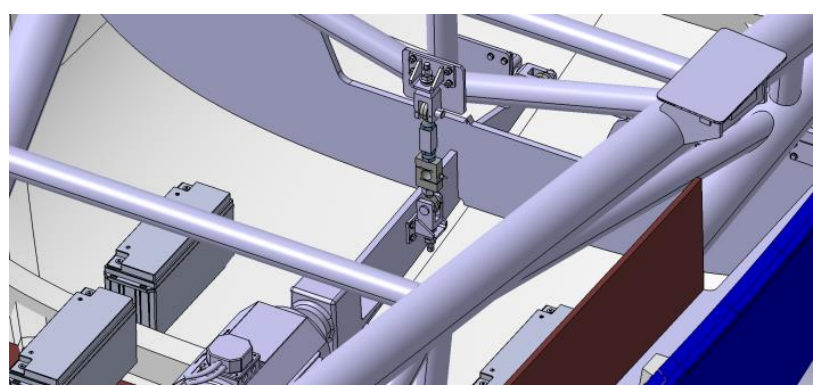

Figure 3: Load cell-frame connection detail 
An additional system which is able to keep the connection between the frame and the hull has been designed and manufactured. This is a safety system based on passive safety rods that keep the frame and the yacht rigging around the nominal position in case of any accidental load cell failure or merely in case of no measure-sailing condition as well as when the sailboat is in the harbour. As reported in Figure 4 the safety rods can be classified as one along $X$ direction (SX), four along Y direction (SY1, SY2, SY3, SY4) and four along Z direction (SZ1, SZ2, SZ3, SZ4).

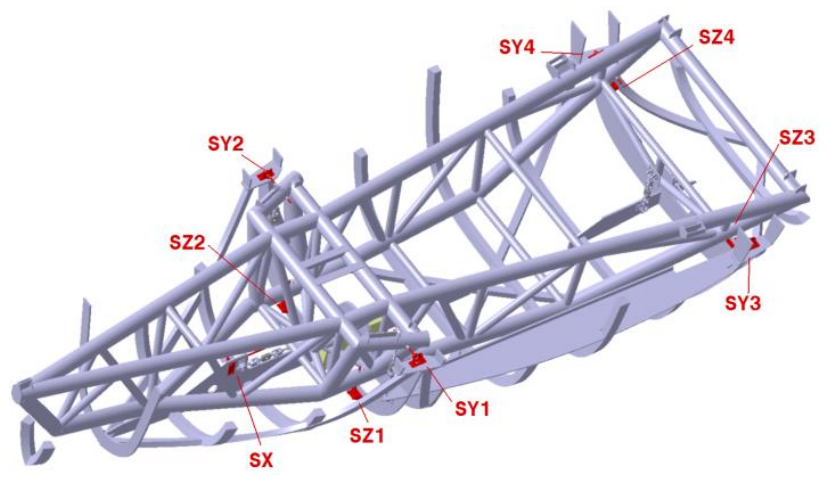

Figure 4: Safety rods arrangement

The safety rods are made of screw bars connected to the plywood bulkheads by means of $\mathrm{C}$ shaped flanges with which large screwed disks come in contact in case of load cells failures (figure 5). These disks can be also screwed tightly to the $\mathrm{C}$ shaped flanges in the no-measure sailing condition (or moored) in order to prevent the load cells from any unpredicted bumps.

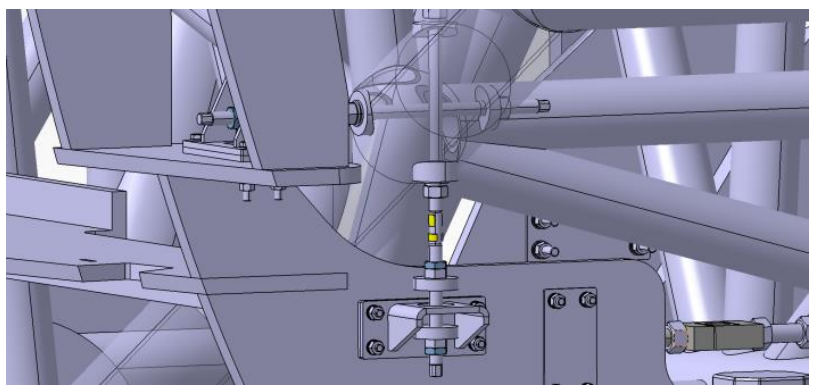

Figure 5: Safety rod concept

\subsection{FRAME STRUCTURAL DESIGN}

After a preliminary assessment of design loads and of rigging elements position on the deck, to define the final frame configuration a multi-objective iterative design process has been performed by means of structural analysis (Finite Element Method) and a 3D CAD tool. This process deals with geometrical constraints as well as with the maximization of the structural resistance, as reported in figure 6.

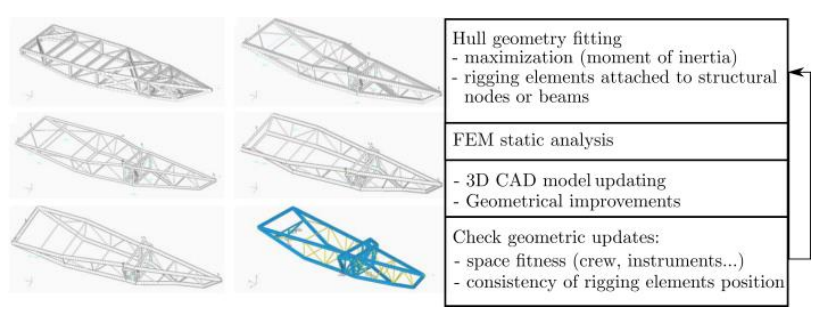

Figure 6: Frame design workflow

The frame was required to fit the hull space as much as possible in order to increase the overall moment of inertia of the structure. Nevertheless, geometrical issues were also taken into account, such as the definition of the elements connecting the rig to the frame in correspondence to nodes or main beams. The finite element structural analysis leads to geometrical modifications that have to be addressed within the $\mathrm{CAD}$ tool, that in turn require further structural 
verifications as well as checking the consistency of the new positions of the attaching points of the rigging and space fitness for crew and instrumentations.

The FEM tool adopted in this work is FEMAP/MSC NASTRAN and figure 7 shows the relevant adopted FE model.

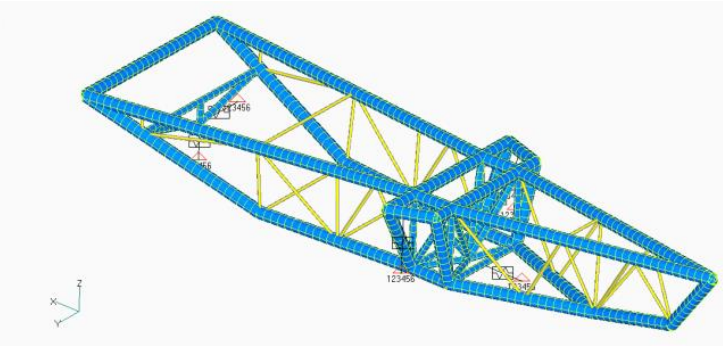

Figure 7:Frame Finite Element discretization.

The choice of the material for the frame structure relies on meeting criteria such as corrosion resistance, greatest stiffness, lowest weight, easy connection among the elements and economical affordability. From a structural point of view the comparison between different materials was carried out by considering a specific parameter, $E / \gamma$, which is the elastic modulus -unit weight ratio, representing the requirement of maximum stiffness and lowest weight simultaneously. Stainless steel and titanium have been discarded for weight and cost, respectively. Carbon fibre tubes have been considered also, but discarded for the highest cost and for the difficulties in connecting the load cells to the frame.

The 5000 aluminium-manganese alloy series was detected as the most compatible material with respect to the requirements: in particular the 5083 series was chosen for the main structural components of the frame, whereas 5086 for the plates welded to the frame whose task is connecting the rigging and the hull to the frame itself.

Figure 8 shows a picture of the final frame design.

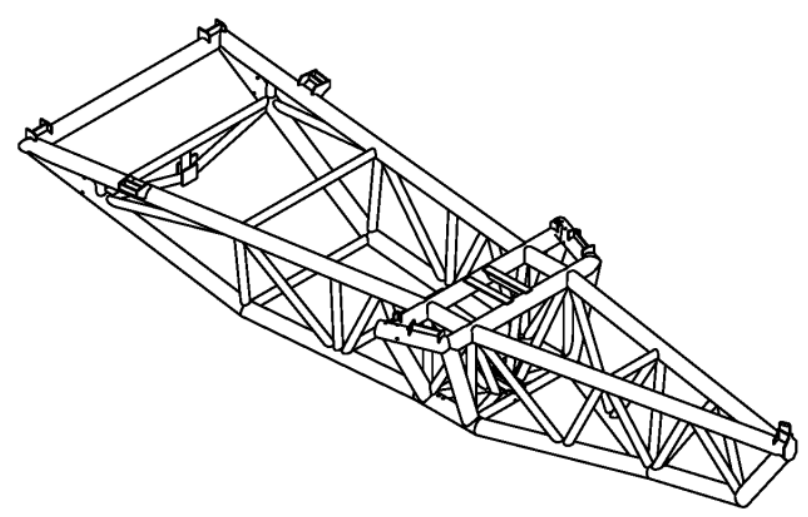

Figure 8:Frame final design

Concerning the manufacturing process, the welded connection between the various beams was made possible by cutting the beams' extremities by means of CNC tools. Then the beams were MIG welded and the whole frame was thermotreated to relax any local stress due to the welding process.

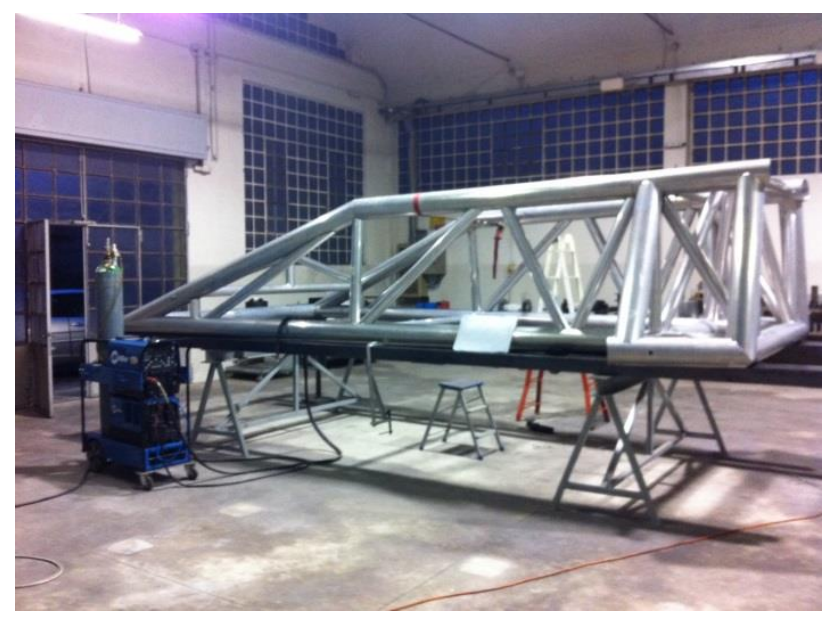


Figure 9:Frame manufacturing

For more details on the frame structural design readers can refer to [34].

3.2

DYNAMOMETER CALIBRATION

The goal of the calibration procedure is to define a "calibration matrix" $C$ :

$\boldsymbol{C}=\left[\begin{array}{llllll}C_{1,1} & C_{1,2} & C_{1,3} & C_{1,4} & C_{1,5} & C_{1,6} \\ C_{2,1} & C_{2,2} & C_{2,2} & C_{2,2} & C_{2,2} & C_{2,2} \\ C_{3,1} & C_{3,2} & C_{3,3} & C_{3,4} & C_{3,5} & C_{3,6} \\ C_{4,1} & C_{4,2} & C_{4,3} & C_{4,4} & C_{4,5} & C_{4,6} \\ C_{5,1} & C_{5,2} & C_{5,3} & C_{5,4} & C_{5,5} & C_{5,6} \\ C_{6,1} & C_{6,2} & C_{6,3} & C_{6,4} & C_{6,5} & C_{6,6}\end{array}\right]$

\section{Equation 1}

that correlates the measurements of the 6 load cells $\underline{S}$ :

$\underline{S}^{T}=\left[S_{x} S_{y 1} S_{y 2} S_{z 1} S_{z 2} S_{z 3}\right]^{T}$

\section{Equation 2}

with the forces and moments $\underline{\boldsymbol{F}}$ referred to the body axes of the boat and reduced to center of mass of the whole yacht:

$$
\underline{F}^{T}=\left[\begin{array}{llllll}
F_{x} & F_{y} & F_{z} & M_{x} & M_{y} M_{z}
\end{array}\right]^{T} \quad \text { Equation } 3
$$

The definition of the elements of the matrix $\mathrm{C}$ is carried out by means of a mimimization process in the unknowns $\mathrm{C}_{\mathrm{ij}}$ as a solution of the over-determined problem over a set of experimental measurements $\underline{S}$ coupled with the corresponding set of known loads $\underline{\boldsymbol{F}}$.

For the calibration tests the boat was set ashore and loads were applied by means of a calibration rig which allows for known load application as shown in figure 10.

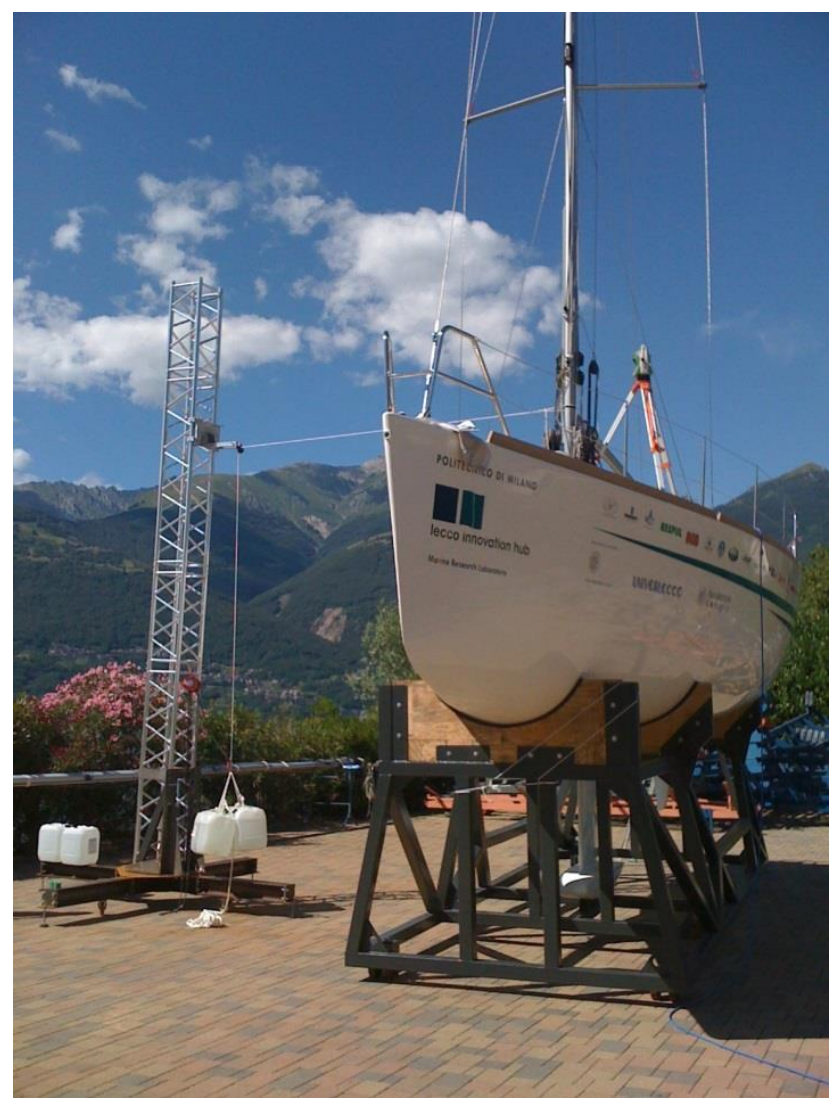

Figure 10:Calibration tests 
More than one hundred loading conditions were applied to the dynamometer up to $2[\mathrm{kN}]$ using water tanks hung to a rope.

For each loading condition the direction of the applied load acting line with respect to the yacht body reference frame must be detected. To this aim the position of the markers M1 and M2 on the rope was measured by a laser total station and the position of a set of marker fixed on the deck was measured too.

More specifically, with reference to figure 11 the marker $\mathrm{P}$ coincides with the point that every item position of the yacht is referred to, and the markers $\mathrm{O}, \mathrm{X}$ and $\mathrm{Y}$ define the trim of the yacht-fixed reference frame with respect to the laserfixed reference frame allowing for the evaluation of the rotation matrix between the laser station fixed (absolute) reference frame and yacht-fixed reference frame.

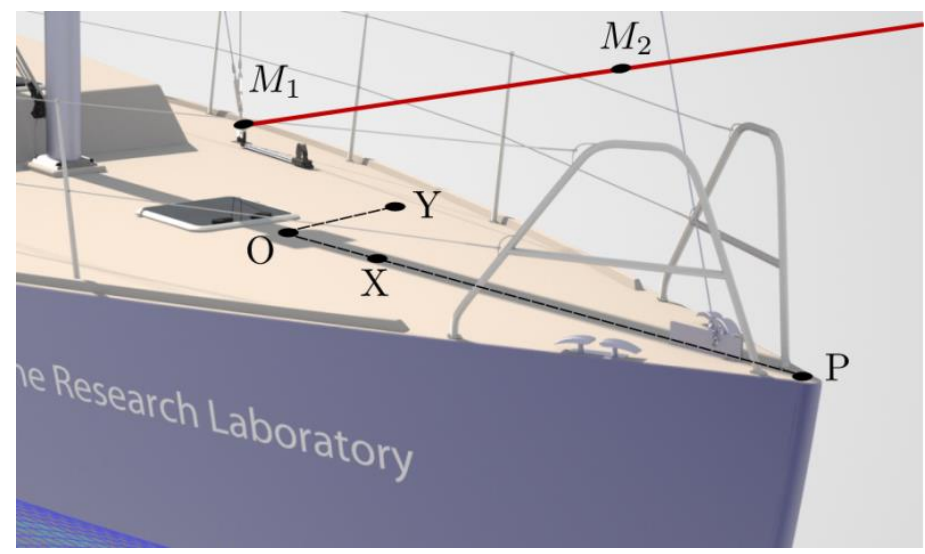

Figure 11:Sketch of the calibration tests.

The definition of the elements of the matrix $\mathrm{C}$ is carried out by means of a mimimization process in the unknowns $\mathrm{C}_{\mathrm{ij}}$ as a solution of the over-determined problem over a set of the experimental measurements $\underline{\boldsymbol{S}}$ coupled with the corresponding set of applied known loads $\underline{\boldsymbol{F}}$.

For the sake of completeness, in the figures 12,13 and 14 , the results of the calibration process are reported. After having defined $\varepsilon_{i}$ and $\xi_{i}$, respectively as the percentage error (nominal force applied Vs force measured) and the direction cosine of the applied load, with respect to the axis $i$, the overall percentage error can be written as:

$$
\varepsilon=\sqrt{\left(\varepsilon_{x} \cdot \xi_{x}\right)^{2}+\left(\varepsilon_{y} \cdot \xi_{y}\right)^{2}+\left(\varepsilon_{z} \cdot \xi_{z}\right)^{2}} \quad \text { Equation } 4
$$

The figures 12, 13 and 14 show, as function of the direction cosines, the magnitude of the overall percentage error $\varepsilon$, coloured accordingly. These graphs must be interpreted as follows: dots on the circle of radius 1 are associated with load cases where the direction of the force has no, or small, component along the remainder axis, which is not depicted in the figure (i.e $\mathrm{z}$ in figure 12., $\mathrm{y}$ in figure 13 and $\mathrm{x}$ in figure 14.), whereas, moving radially to the centre of the disc, the third component increases to the limit of the centre of the circle, where the direction of the load is completely along the third direction.

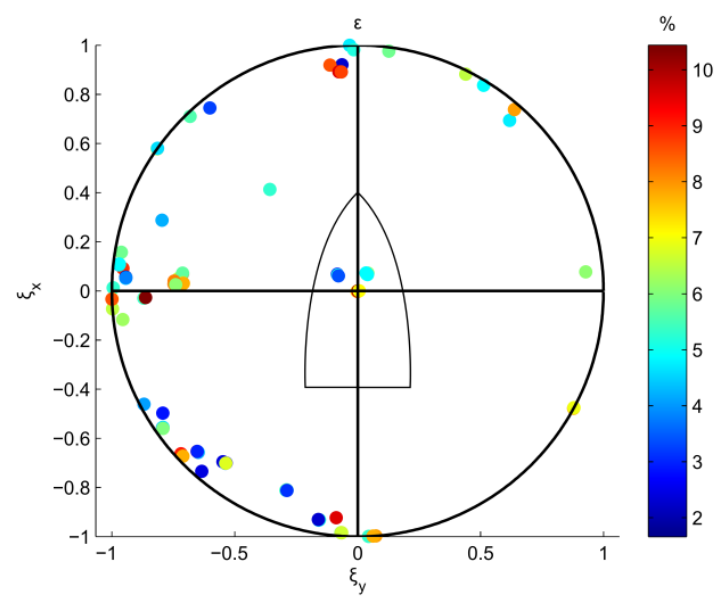

Figure. 12: Dynamometer accuracy over the xy plane 


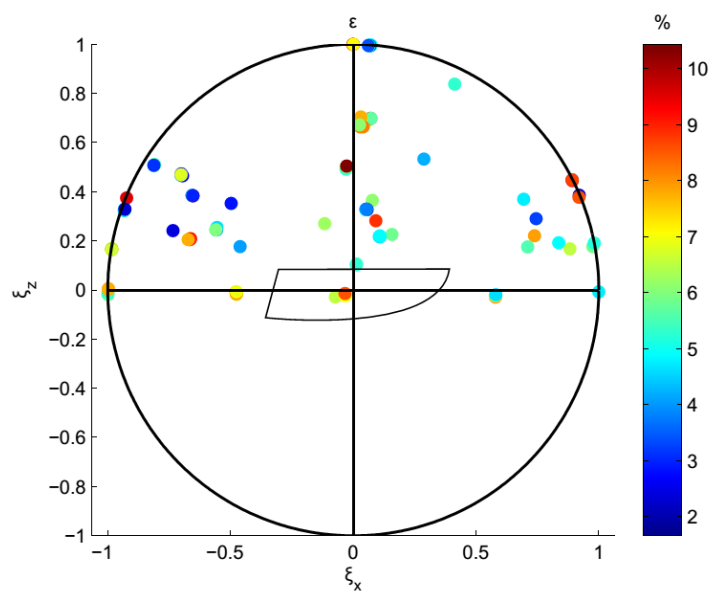

Fig. 13: Dynamometer accuracy over the xz plane

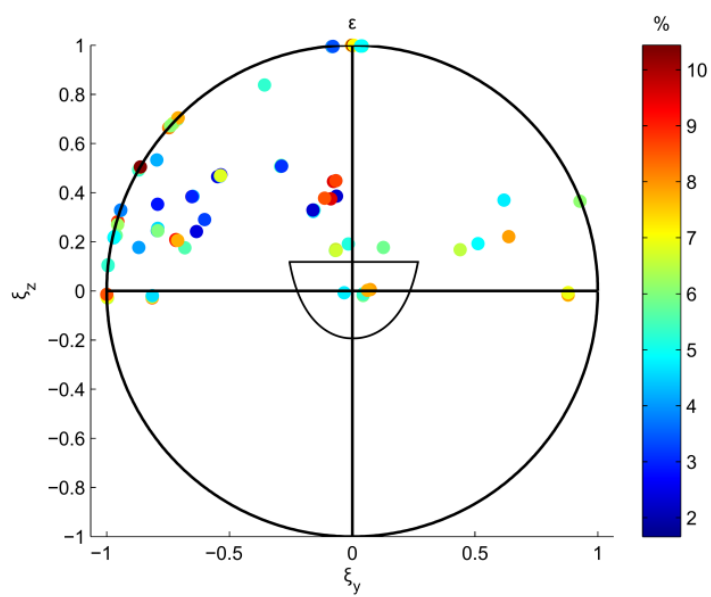

Fig. 14: Dynamometer accuracy over the yz plane

As can be seen obtained errors are included in the [2\%-9\%] range and in any case less than $10 \%$ which should provide an adequate performance of the dynamometer.

\section{THE SAILING LAB DESIGN AND CONSTRUCTION}

\subsection{CONCEPT DESIGN}

The Sailing Yacht Lab project was entirely developed and managed by a team of researchers in the Mechanics Department of the Politecnico di Milano.

In figure 15 the design moduli for LIH Sailing Yacht Lab design are reported. Some of them are within standard yacht design procedure while 2, 6 and 10 are peculiar of the boat mission profile. Main dimensions have been defined in coherence to the $9,99 \mathrm{~m}$ LOA limit given by Italian regulation that in this case does not require any navigation document.

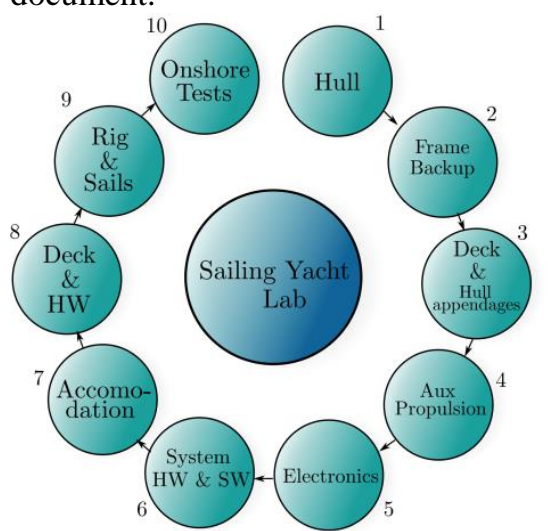

Fig. 15:Sailing Yacht Lab project workflow. 
Hullform and main charcteristics must provide adequate sailing performance as well as a fair behaviour in term of form stability and seakeeping. The choice to use lines from Comet 35 produced by COMAR YACHTS (figure 16) is related also to GRP bare hull shell availability (figure 17); nevertheless the project has not suffered any constrain due to the use of an existing boat.

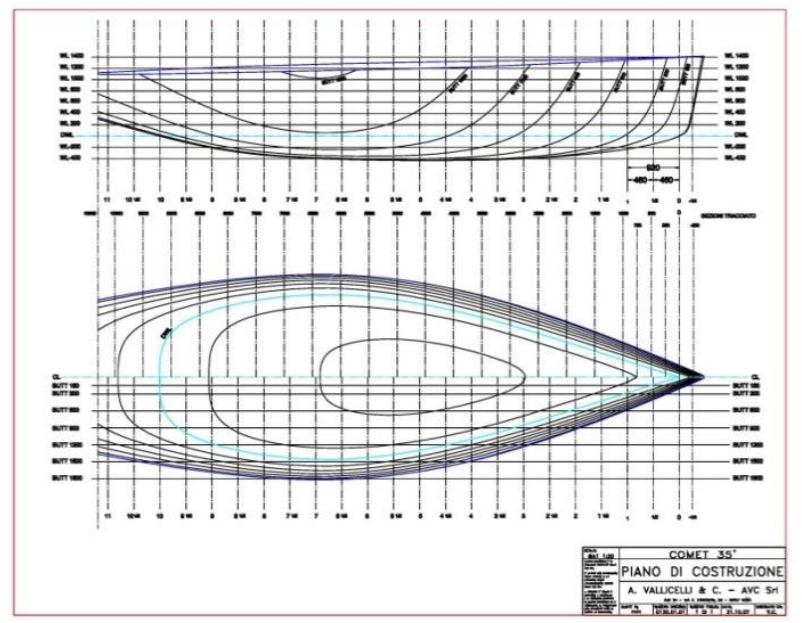

Figure 16: Comet 35 hull design lines

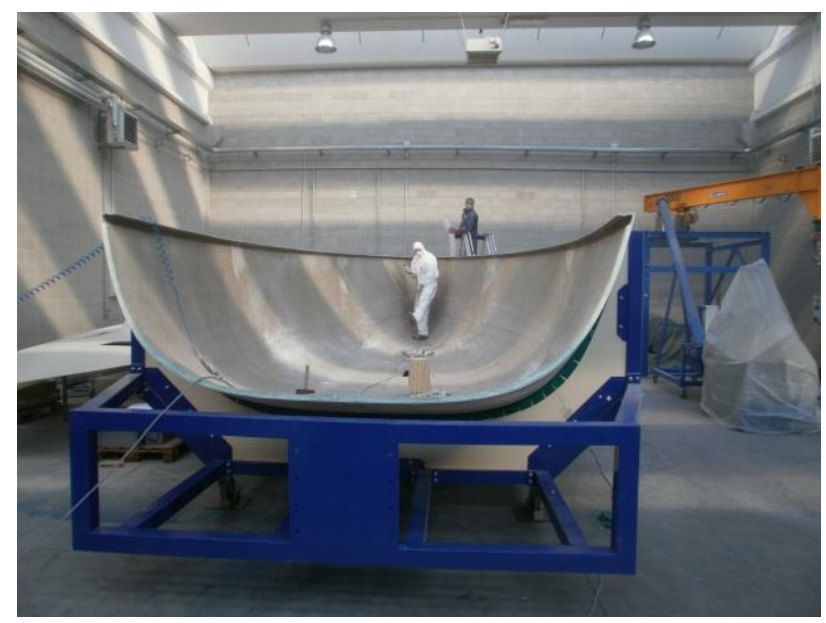

Figure 17:Hull shell preparation

Quite different has been the approach to structural design. This is deeply influenced by boat peculiar tasks and by the light alloy frame, shaped to fit rig and rigging geometries.

Plating stiffeners, both transversal and longitudinal have been completely redesigned according to the identified load cells positions (figure 18 and 19).

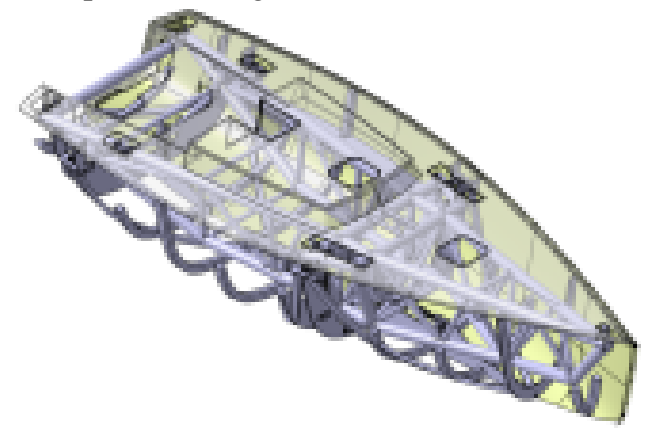

Figure 18:Hull-frame concept 


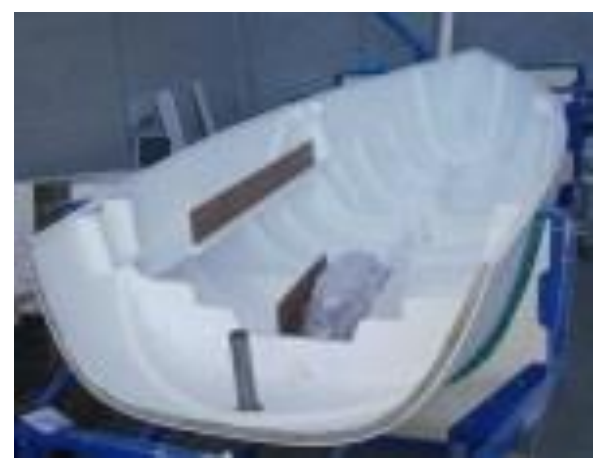

Figure 19:Hull internal structures

Deck lines have been custom designed also. This is due to the strong interactions of deck lines with the light alloy frame and to the necessity of a very large open cockpit. Obviously, the deck layout of a production boat was very far from that. Deck, cockpit and doghouse have been laminated in a single piece of GRP sandwich using a one-off plywood mould (figure 20).

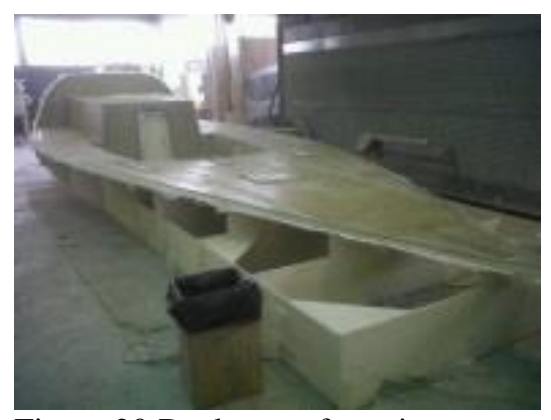

Figure 20:Deck manufacturing

An internal case with trapezoidal longitudinal and transversal sections has been used for ballast keel attachment. This solution is most effective when keel section is very thin and, most important for this boat, it allows a $200 \mathrm{~mm}$ keel longitudinal shift in case of different sail plan to be tested (figure 21).

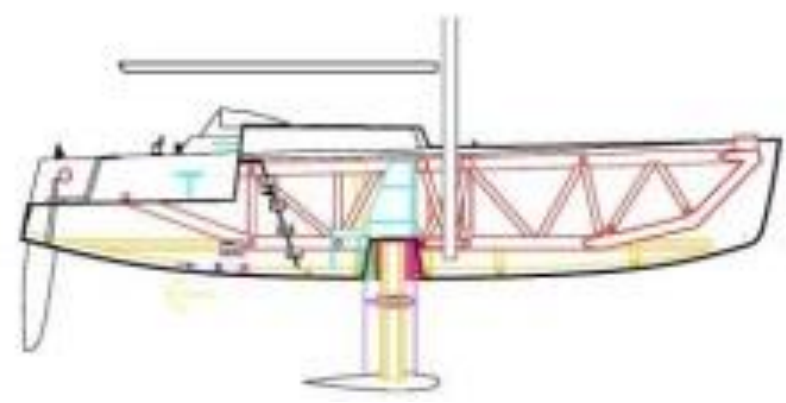

Figure 21:Sketch of the keel internal structures

The ballast keel consists in a wing with constant NACA 65 section and a cast lead ballast (figure 22). The keel structure is made by a double $\mathrm{C}$ welded AISI 316 beam with $10 \mathrm{~mm}$ thick walls, while CMC machined high density polyurethane foam provides the right shape according to the chosen profile. A $2 \mathrm{~mm}$ thick skin of glass/epoxy is used to get adequate surface hardness.

The ballast lead has been cast in closed mould made from a CNC shaped wood model. This allowed a perfect shape and surface of the lead torpedo without any manual fairing. The transversal sections of the ballast lead are designed to give lowest possible CG position. The use of the internal case for the keel fixing allows a very easy mounting with just two bolts and a self aligning mounting. The keel moment will be transferred to the hull structure through teak wedges bolted to the stainless steel beam upper part. 


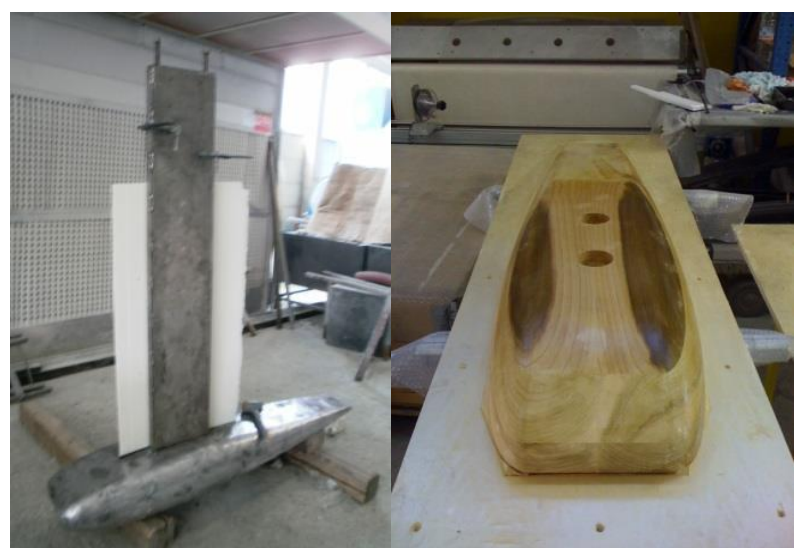

Figure 22:Keel manufacturing

Once the light alloy frame was manufactured it was directly assembled within the hull providing load cell alignments with the relative hull structures (figure 23).

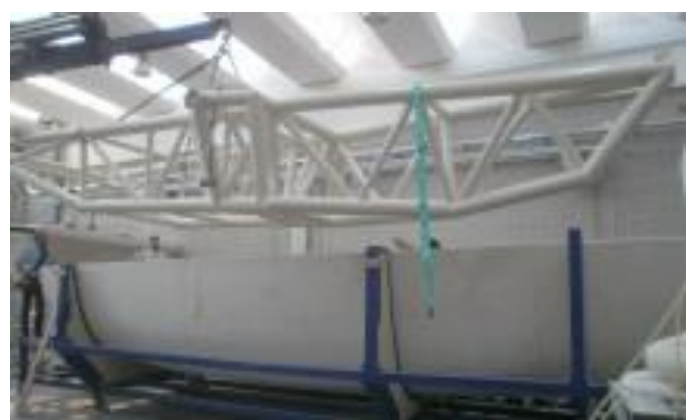

Figure 23: Frame-Hull assembly procedure

The last peculiar design feature of this project is related to the internal waters where the boat will be used.

The Sailing Yacht Lab is a sustainable, non-invasive project that is compatible with the ecosystems in which the boat will operate. A zero emission electric auxiliary propulsion has been designed using standard production elements, to allow three hours range at five knots cruising speed in calm water (figure 24).

The Sailing Yacht Lab will also be a testing ground for the further development of electrical propulsion in the nautical sector, especially as concerns the storage of electrical energy and the use of renewable sources.

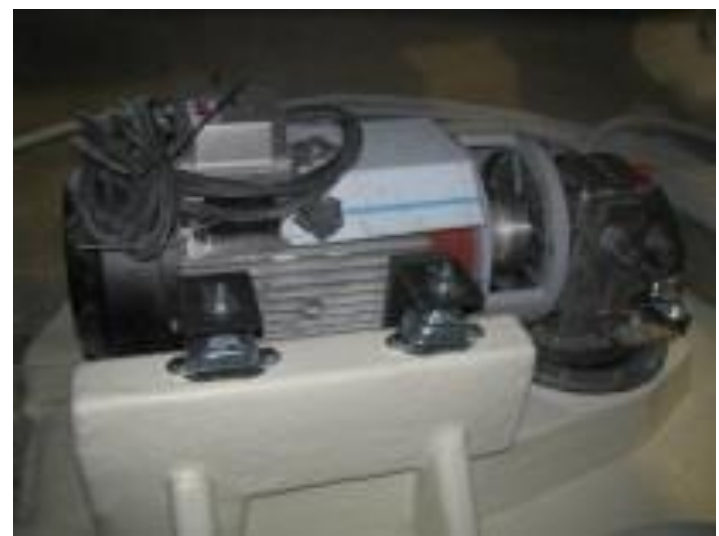

Figure 24:Electric motor

\subsection{BUILDING PROCESS}

The construction has been entirely carried on by the Department of Mechanics staff (figure 25) within Lecco Innovation Hub facilities (figure 26). One off construction is very common in yachting. The most of large racing yachts are built this way. In this case the most important - and difficult - task of the building team has been to assure the perfect alignment of the cinematic chain containing the load cells to the designed directions. 


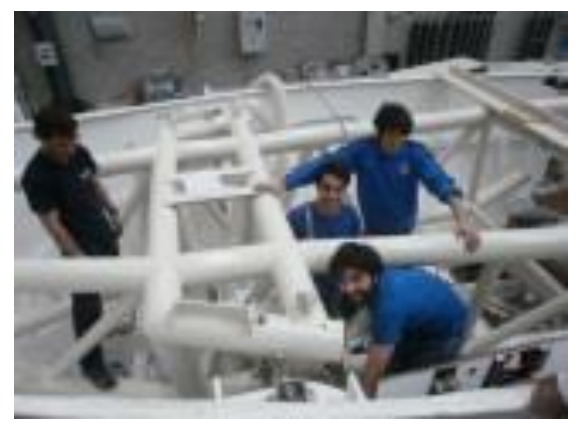

Figure 25:PoliMi students and researchers at work

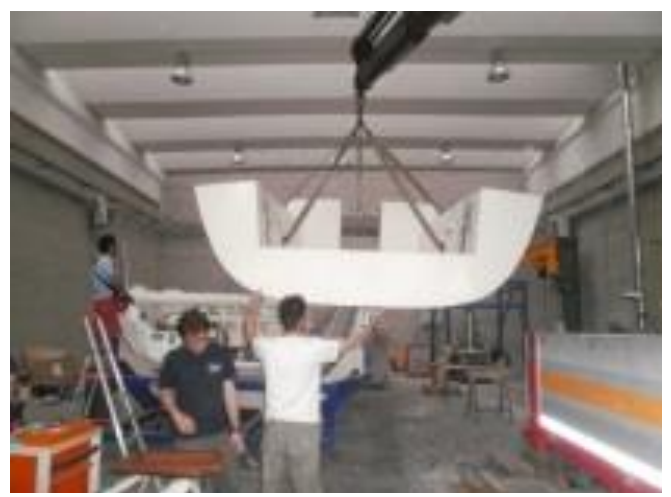

Figure 26:Deck assembly

To this aim the GRP hull shell has been bolted to a dedicated cradle, (Fig. 27) to get a permanent reference during the whole construction.

The frame geometry and mass properties have been controlled before mounting it as well as the load cell alignments with the relative hull structures (figure 28).

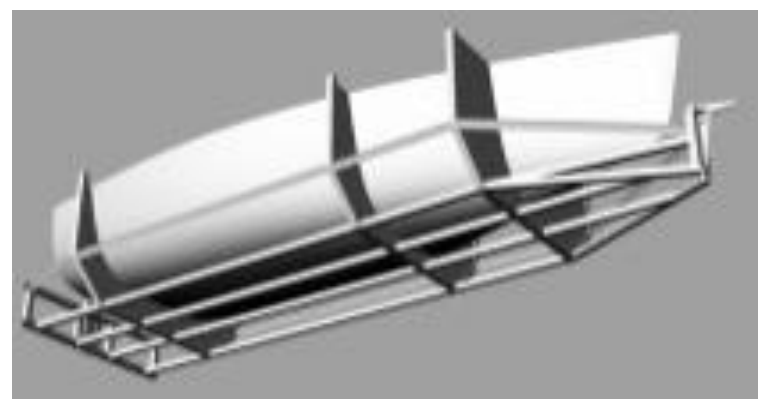

Figure 27:Hull supporting structure design

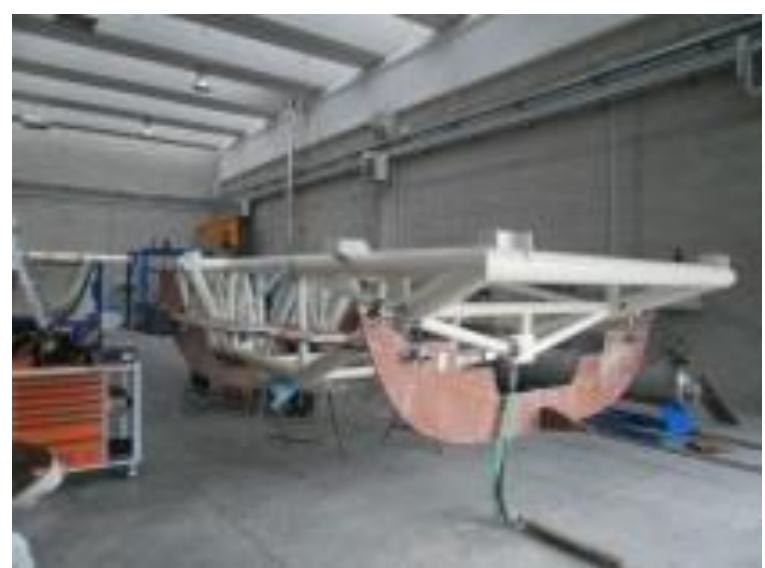

Figure 28: Frame-structures preliminary alignments 


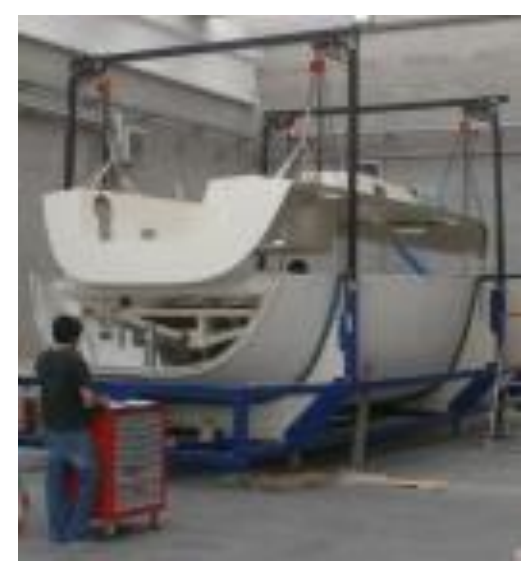

Figure 29:Deck-frame-hull preliminary alignments

In the following Table 1 the most important prefabricated elements and the considered check points are reported.

\begin{tabular}{|c|c|}
\hline Purchasing/Prebuilding & Check points \\
\hline Hull shell purchasing & \\
\hline - Cradle construction & Hull aligned \\
\hline - Deck mould & Deck completed \\
\hline - Deck lamination & Dеск Сопріете \\
\hline Cutting frame components & \\
\hline $\mathrm{CNC}$ & Frame completed \\
\hline - Frame welding & \\
\hline - Frame geometry check & \\
\hline $\begin{array}{l}\text { Engine-sail drive coupling } \\
\text {. Engine installation }\end{array}$ & Engine installed \\
\hline - Hull transversal framing & Frame-cells-structure alignment \\
\hline - Load cells fittings & check \\
\hline · Hull longitudinal stiffeners & Frame mounting - cell alignment \\
\hline . Hull transversal framing & check \\
\hline - Deck custom hardware & Preliminary deck check - deck \\
\hline - Accommodation & removed \\
\hline & Genoa Boat Show \\
\hline $\mathrm{Hw} / \mathrm{Sw}$ installation & $\begin{array}{l}\text { Load cells system preliminary } \\
\text { check with boat upright and } \\
\text { heeled }\end{array}$ \\
\hline Deck mounting & \\
\hline - Outside decoration & Hull and deck completed \\
\hline - External/internal details & \\
\hline - Rudder shaft/Rudder blade & \\
\hline . Keel structure/Feel fairing & Rudder and keel set \\
\hline - Ballast model/Ballast cast & \\
\hline - Rig and Sails set up & Ready to sail \\
\hline
\end{tabular}

Table 1:Yacht construction main steps

\subsection{PROJECT MANAGEMENT AND COMMITTING}

When building prototype or experimental craft the project management is a critical factor and it is very much influencing to get the expected result in terms of quality, time and budget.

The options for a successful and effective building process are basically two. The most common is to identify a main contractor that will take care and responsibility of the whole building process although allowing external contributes for specific yacht features. The second is to manage several contractors one for each yacht feature and merge these contributes together to get the final result.

Although more risky and complex this last one is more flexible to design changes and has been considered preferable for this project where almost no reference was available. It is evident that in this case the influence and responsibility of the project manager are most important and he must have specific experience and skill. 
The general policy of building process of SYL has been to manage separately the different subcontractors and to merge them according to identified steps in which partial results could be checked. This approach is very sound when the quality of the results is the primary target but generally hardly complies with sharp deadlines.

Finally SYL as any prototype or experimental craft can never been considered completed, but only ready for the next scheduled task. Furthermore, the acquisition system needs periodical tuning and setting. For these reasons a dedicated logistic has been provided. It allows any type of preparation and set up to be done ashore, adequately supported.

\section{EXPERIMENTAL APPARATUS}

In the following the Sailing Yacht Lab measurement set up and data collection system architecture will be briefly described.

\subsection{FORCE MEASUREMENTS}

Force measurements are carried out by means of strain gages based mono-axial HBM S9M load cells. The conditioning system is given by a Burster 9235 module for each load cell, implementing a full-bridge 6-wire conditioning configuration. The protection class of the load cells and conditioning modules are respectively IP40 and IP68, that could be considered adequate for this kind of application. The load cells are also highly accurate and highly stable with respect lateral force.

Load cells signals are converted from analog to digital by means of National Instruments technology through a 9178 9205 chassis-analog input module.

\subsection{YACHT TRIM AND MOTION MEASUREMENTS}

A 3DM-GX3-35 GPS-aided inertial navigation system consisting of an Attitude and Heading Reference Unit (AHRS) and a Global positioning System (GPS) receiver is used to measure the yacht attitude and boat dynamics. The sensor used are gyroscopes, accelerometers and magnetometers and are arranged on the three primary axes to acquire angular rate, acceleration and the local magnetic field respectively.

The system can communicate to the host via USB providing position velocity and attitude estimation in digital format according to a specific Data Communication Protocol.

The heel and trim angles are also measured using a GEMAC 23554 analog inclination sensor that is analog-to-digital converted along with the load cells signals by means of the same converter. This sensor provides information of the rotation along two perpendicular planes, that turn out to be pitch and roll. The inclination sensor is installed just beside the inertial navigation system in order to compare analog Vs digital signals of the same quantities (Euler angles):

\subsection{NAVIGATION DATA}

A classical navigation equipment is also installed providing wind speed and direction, boat speed, depth as well as the yacht course by means of a differential GPS receiver.

The navigation system support the NMEA 2000 and can communicate to the host via NMEA 183 standard protocol

\subsection{WIND MEASUREMENT}

In addition to the mast top anemometer an ultrasonic 3D anemometer is mounted on the top of an additional mast which is set on the yacht bow and which keeps the vertical position irrespective of the boat heel.

Using this device the additional anemometric measure is performed in the corresponding sailplan geometric center of effort height and the 3 wind speed components are provided by means of analog signals.

\subsection{SAIL FLYING SHAPE MEASUREMENTS}

The Lecco Innovation Hub Sailing Yacht Lab is fitted with the "LIH TOF Flying Shape Detection System" [20,21] which provides the 3D sail geometry in actual sailing conditions.

This system relies on Time Of Flight (TOF) technology and, in particular, a laser scanner was selected to ensure high measurement accuracy and speed. The scanner emits a laser pulse in a certain direction, and estimates the target distance by evaluating the time the pulse takes to return to the sensor. The device is equipped by an internal mirror that deflects the laser pulse triggering the acquisition with regular angular step of minimum $0.167^{\circ}$ or maximum $1^{\circ}$. Its operating range goes from $0.5 \mathrm{~m}$ to $80 \mathrm{~m}$ covering an angular section of $190^{\circ}$ from $-5^{\circ}$ to $185^{\circ}$ (figure 30 ).

\footnotetext{
${ }^{1}$ Patent application n ${ }^{\circ}$ PD2014A000249 ([20],[21])
} 


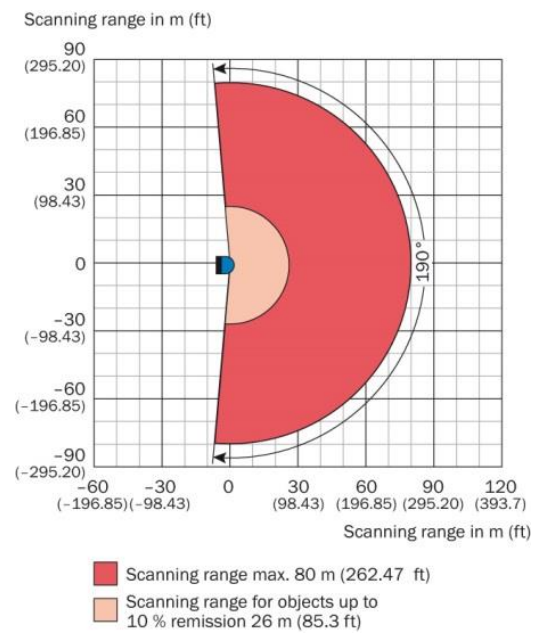

Figure 30: Flying shape detection system: scanning range.

Moreover, the 5-echo technology can be enabled ensuring the reliability of the measurements even in outdoor bad weather conditions such as rain, fog and dust.

The selected TOF device provides information about the measured points in terms of polar coordinates: for each detected point a radius $r$ and an angle $\alpha$ are provided with reference to the origin of the coordinates system located on the internal mirror rotational axis (figure 31 ).

Due to its intrinsic characteristics, the laser scanner is able to measure only points lying in the same plane while in this particular application the entire sail surfaces has to be measured.

To overcome the problem, a dedicated handling unit based on a brushless motor and an epicyclical gear has been developed to enable the controlled rotation of the measurement device around an axis perpendicular to the TOF mirror rotational axis. A proximitor is used to identify the initial scanning position for each data acquisition.

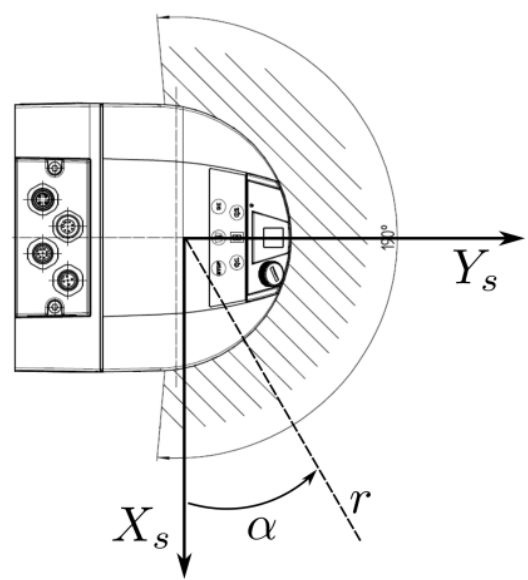

Figure 31 Flying shape detection system.

Figure 32 shows the complete TOF Flying Shape Detection System.

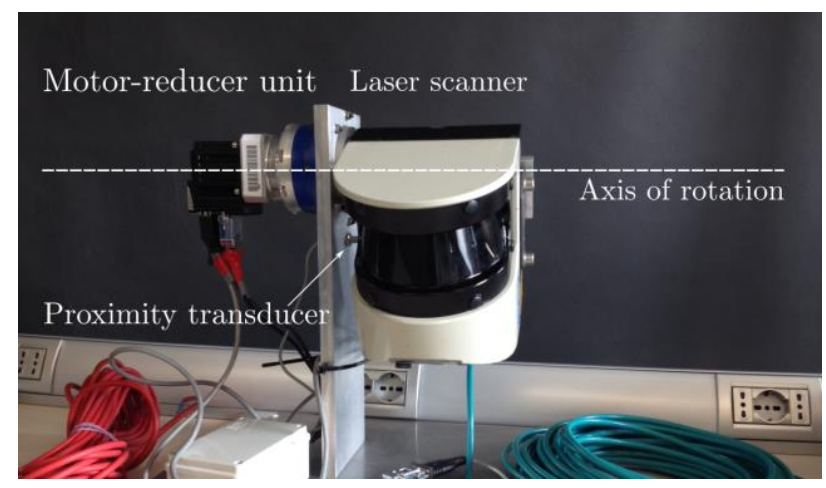


An in house software has been developed allowing for the handling unit control strategy. Through the realized user interface (figure 33) it is possible to: control the brushless motor via serial port (setting velocity and acceleration), establish the connection to the laser scanner and acquire data from it via Ethernet port using TCP/IP protocol, set the scanning parameters, such as starting angle and angle to be scanned, receive and external trigger to automatically run the scanning (useful for synchronous acquisition of different devices controlled by a common unit control). Measured data are saved onto a personal computer hard disk.

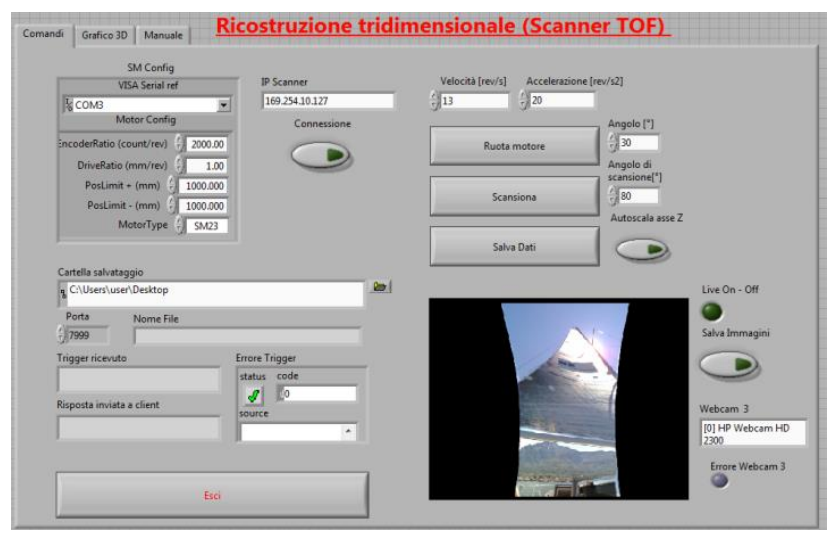

Figure 33 TOF acquisition system snapshot

Using the "TOF Flying Shape Detection System" the sail shape 3D geometry in terms of point cloud where the 3D coordinates in an absolute frame is measured for each individual point and the full 3D coordinates of each individual point belonging to the sail surface are stored for IGES file creation.

In addition, a real time analysis on a limited number of sail surface sections can be performed providing section camber, draft, entry, exit, front, back and twist relative to yacht centerline.

These values are output to file and displayed on the system interface allowing the evaluation in real time of boat performance as a function of the sail trimming parameters.

More details on the LIH TOF Flying Shape Detection System can be found in [19].

\subsection{SAIL PRESSURE MEASUREMENT}

An important feature of the project is the availability of systems for measuring the loads acting on the sails at full scale. The possibility of knowing the effective pressure distribution over the sail plan is of great interest for the aerodynamic and structural design of sails, and also for the selection and optimal use of materials and production techniques. Integral measurements alone may not be sufficient for an understanding of how to use a sail plan if it is not possible to determine the complex interactions they provoke. On the Sailing Yacht Lab, the pressure distribution on the sails is carried out by means of MEMS sensors (an excellent compromise between size, performance, costs and operational conditions) and dedicated pressure pads which have been designed and produced aiming to provide the differential measurement between the sail leeward and windward side.

The pressure pads are single point measurement spots which can be individually placed on the sail and connected to the pressure scanner box with small tubing fixed in a custom build sleeve on the sail.

With reference to the SYL sail inventory figures 34 and 35 show the sail pressure measurements sections and the relevant number of pressure taps. 


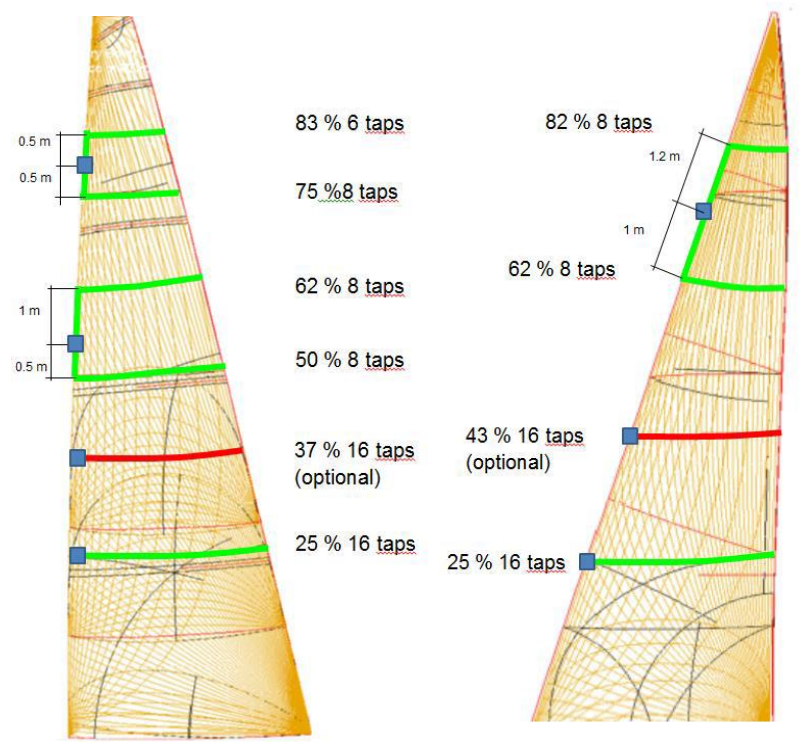

Figure 34 Mainsail and jib pressure taps layout

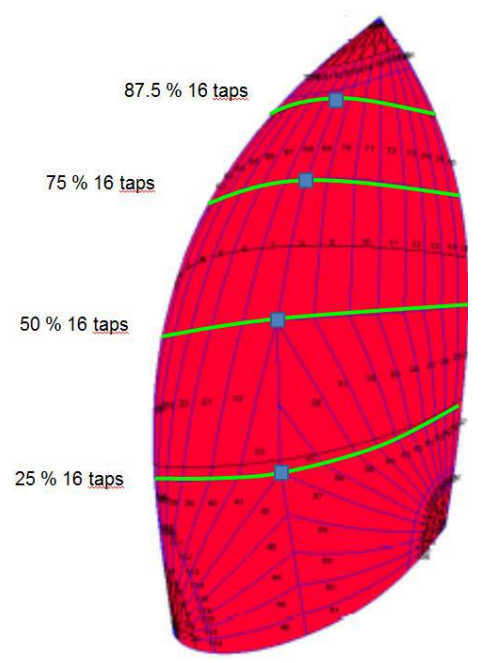

Figure 35: Gennaker pressure taps layout

In figures 34 and 35 the pressure scanner boxes positions are shown with reference to each sail.

Tab 2 shows the pressure scanner specifications:

\begin{tabular}{|c|c|c|c|}
\hline Parameter & Z16 & Unit & Comment \\
\hline FS Pressure Range & \pm 1000 & $\mathrm{~Pa}$ & $2000 \mathrm{~Pa}$ dynamic range \\
\hline $\begin{array}{l}\text { Number of pressure } \\
\text { sensors }\end{array}$ & 16 & & $\begin{array}{l}\text { Differential pressure sensors, } \\
\text { both sides of each sensor } \\
\text { membrane routed to an } \\
\text { individual tap }\end{array}$ \\
\hline $\begin{array}{l}\text { Measurement } \\
\text { Resolution }\end{array}$ & 0.1 & $\mathrm{~Pa}$ & \\
\hline $\begin{array}{l}\text { Static accuracy after } \\
\text { zeroing }\end{array}$ & 0.5 & $\% \mathrm{FS}$ & $\begin{array}{l}\text { Includes the combined errors of } \\
\text { non-linearity, hysteresis and } \\
\text { repeatability }\end{array}$ \\
\hline Total thermal error & 0.05 & $\% \mathrm{FS} /{ }^{\circ} \mathrm{C}$ & Zero and span relative to $25^{\circ} \mathrm{C}$ \\
\hline Sampling rate & $1-20$ & $\mathrm{~Hz}$ & Per channel \\
\hline Input Voltage & $5-12$ & $\mathrm{~V}$ & Supplied over CAN cable \\
\hline Stand by current & 10 & $\mathrm{~mA}$ & Sleep mode \\
\hline Operation current & 40 & $\mathrm{~mA}$ & Scanning mode \\
\hline Communication & CAN interference & & $\begin{array}{l}1 \text { Mbit /s - Daisy Chain } \\
\text { Topology }\end{array}$ \\
\hline $\begin{array}{l}\text { Calibrated } \\
\text { temperature range }\end{array}$ & 5 to 40 & ${ }^{\circ} \mathrm{C}$ & Optional -30 to $60^{\circ} \mathrm{C}$ \\
\hline Size & $65 \times 50 \times 5$ & $\mathrm{~mm}$ & $\mathrm{~L} \times \mathrm{W} \times \mathrm{H}$ \\
\hline Weight & 50 & gram & Aluminum housing \\
\hline
\end{tabular}

Tab 2: Pressure scanner specifications 
and in figure 36 a picture of the pressure pad is reported.

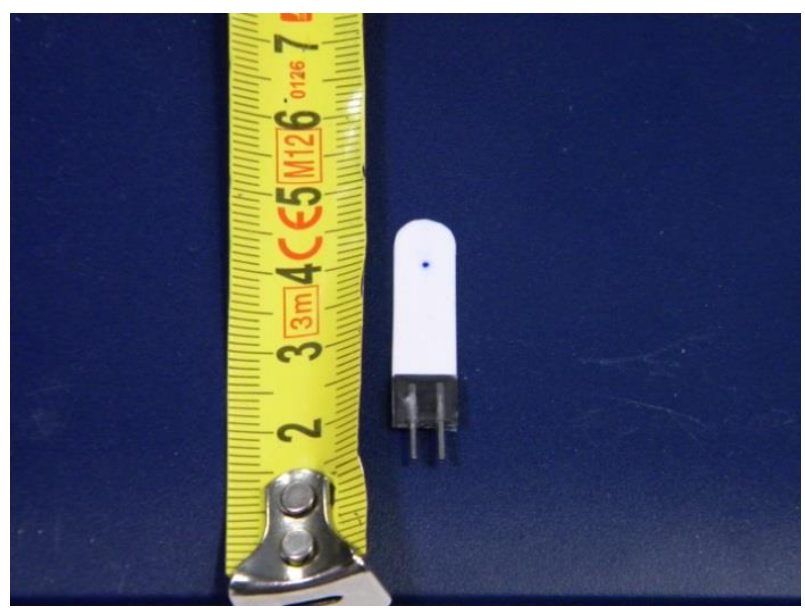

Figure 36 Pressure tap

At the moment this paper is going to press the pressure measurement system is under testing in the Politecnico di Milano Wind Tunnel using the yacht scaled model described in [1].

\subsection{DATA RECORDING EQUIPMENT: REAL TIME AND SYNCHRONIZATION}

The data recording system relies on a main software, developed in c\# and Intempora ${ }^{\circledR}$ programming environments, with the aim of acquiring signals/data as well as managing, triggering and synchronizing other measuring systems as reported in the figure 37.

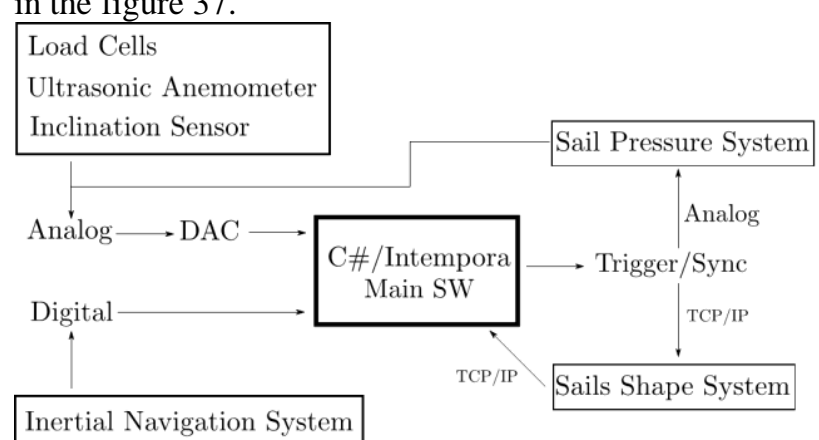

Inertial Navigation System

NMEA-GPS

Figure 37: Dynamometer/Sail Shape acquisition software flowchart

More specifically, a graphical user interface (GUI) is developed in c\# and coupled with Intempora®, which is dedicated to the synchronization of different type of signals (Analog Vs Digital) and differently sampled signals (i.e Load Cells Vs NMEA). For the sake of completeness the sampling frequency of the load cells is kept as reference for every other devices, included the sub-sampled ones (i.e NMEA). For the latter, Intempora is devoted to hold and produce the same sample waiting for the new value, that will be available after a time interval that is also unpredictable. During the navigation, the user (and the crew) is able to watch at every single signal that is running in real time, by means of the above mentioned main GUI (figure 38). 


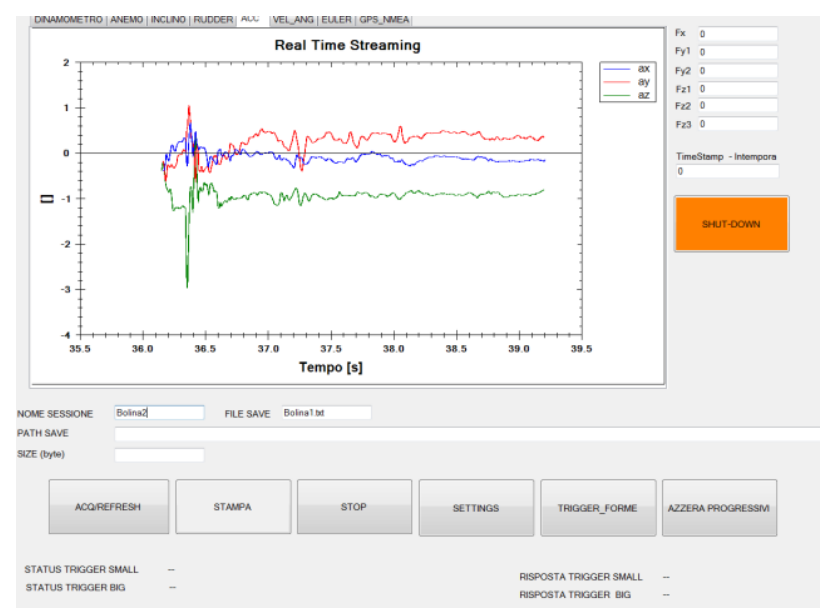

Figure 38 Dynamometer/Sail Shape acquisition software snapshot

Then, whenever the user decides to start to save a new time history, the acquisition system must to be enabled and user can also decide whether triggering the other separate acquisition systems (i.e Sail Shape), also in different and multiple moments of the time history. A "txt" file is then stored with the time history of each device, collected by columns, and "log" file, containing various information (e.g tcp/ip communication success of the triggering commands), is consistently compiled during the experimental session.

\section{SOME EXAMPLES OF GATHERED DATA}

In the following some examples of measurements collected during one of the first trial sessions are reported (figure 39). Trial tests have been carried out offshore Colico Marina in the north of Como Lake where SYL is based, in southerly wind and quite flat water.

Reported data are relevant to a close hauled sailing course with just the mainsail hoisted and to a "stable" time window of about 70 second extracted from a 4 minute data acquisition period.

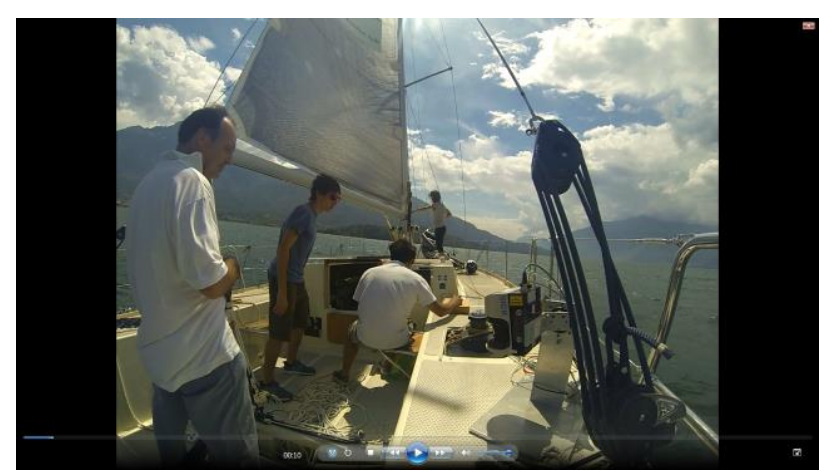

Figure 39: Experimental session

Figure 40 shows the measured true heading angle and figure 41 shows the corresponding apparent wind angle and apparent wind speed. 


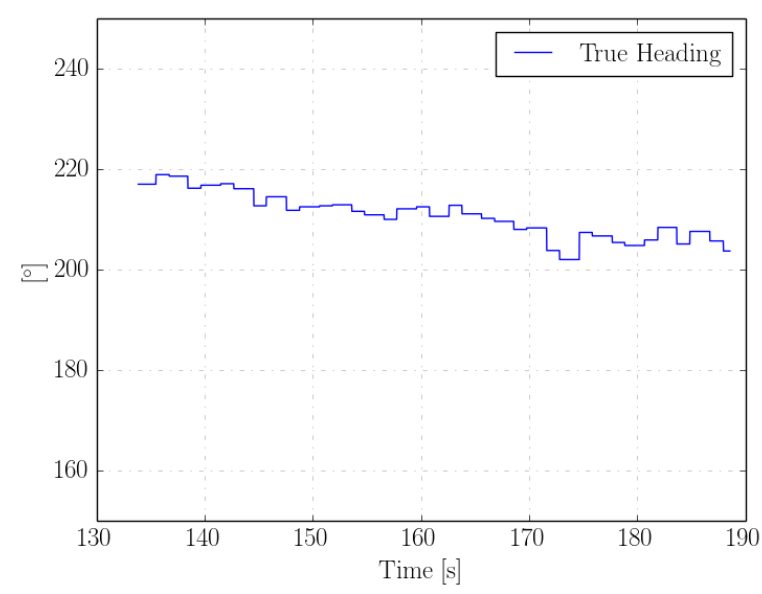

Figure 40:True heading of a sample time history
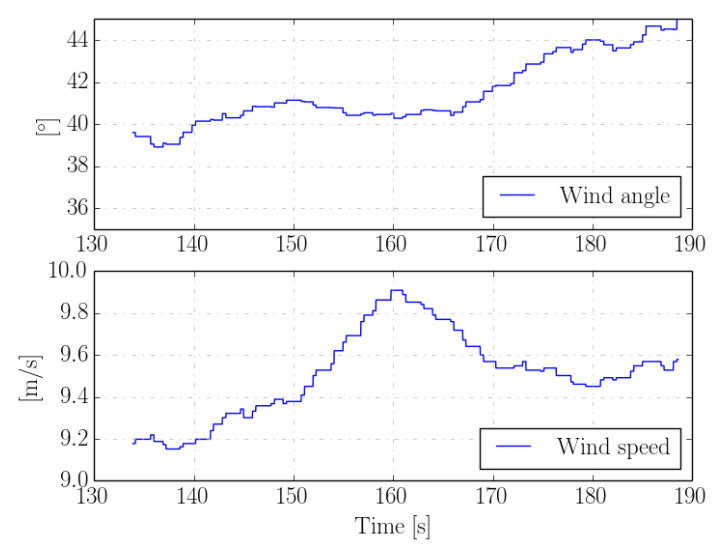

Figure 41 Wind angle and wind speed of a sample time history

Figure 42 shows the correspondent boat speed measured by means of the boat log in comparison with the speed over ground measured by the GPS.

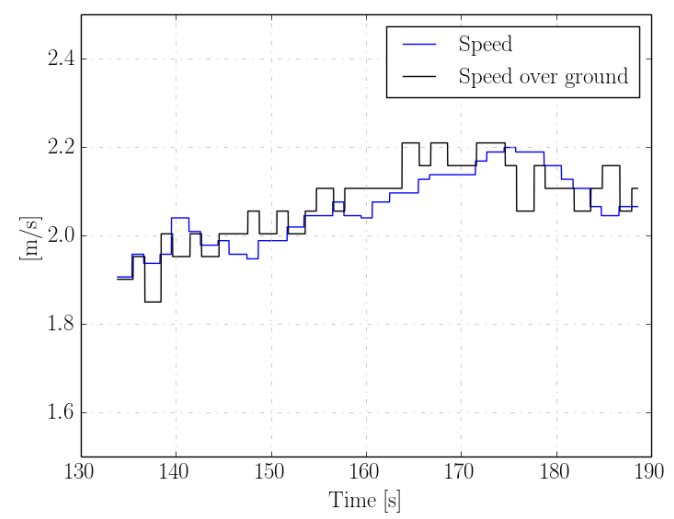

Figure 42 True speed and speed over ground of a sample time history

Figure 43 shows the rudder angle and the boat pitch and roll measurements. In figure 44 the measured aerodynamic forces and moments referred to the body axes of the boat are reported while figure 45 shows the vertical and longitudinal measured positions of the aerodynamic centre of effort compared with the geometric estimated values. 


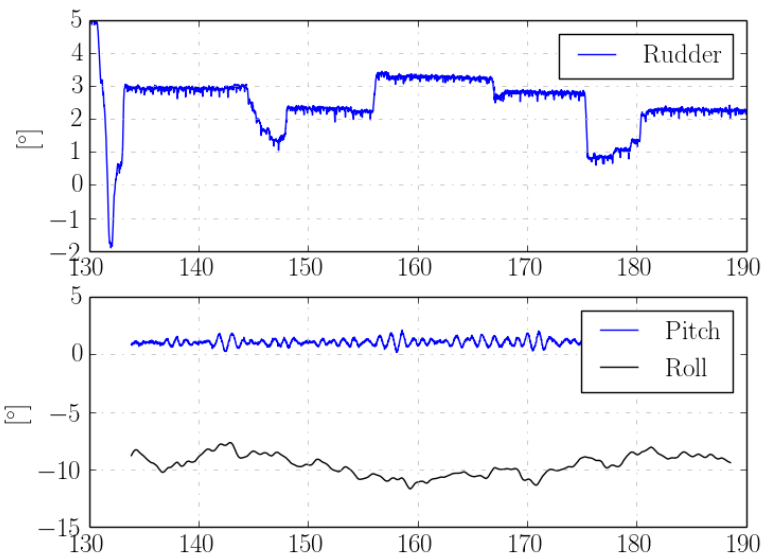

Figure 43 Rudder angle, pitch and roll of a sample time history
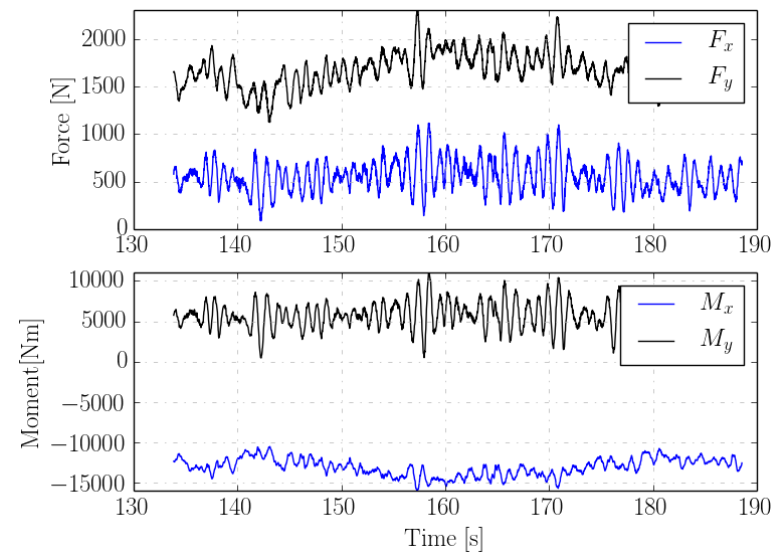

Figure 44 Aerodynamic forces and moments of a sample time history

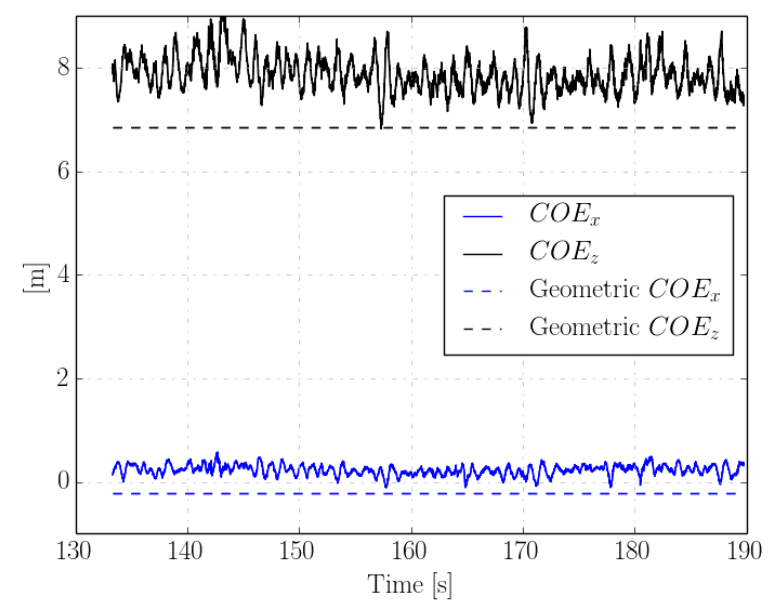

Figure 45 Measured centers of effort Vs geometric centers of effort, of a sample time history

As far as the sail flying shape measurements are concerned, figure 46 shows an example of the point clouds (respectively of the mainsail and the jib) directly measured on board by means of LIH TOF Flying Shape Detection System and figure 47 shows the 3D surface obtained after the segmentation and surface fitting procedures. 


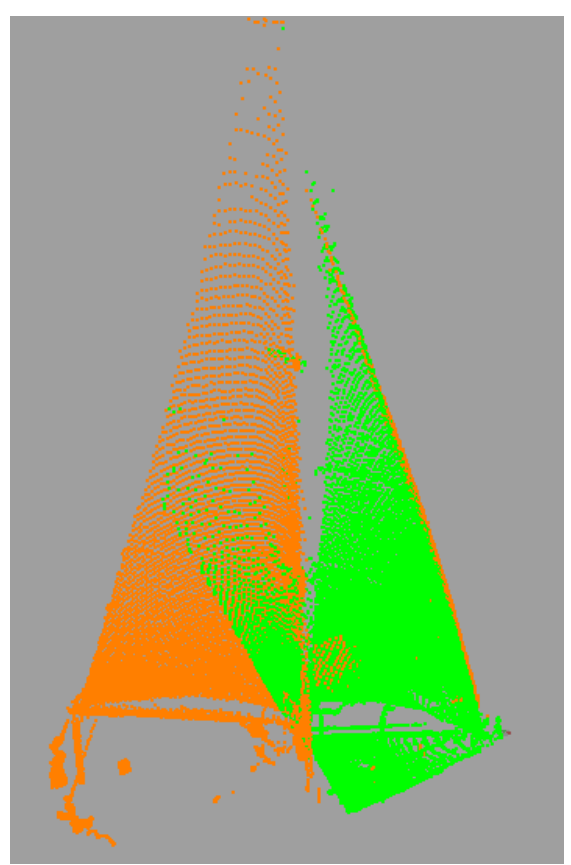

Figure 46 TOF output: point cloud

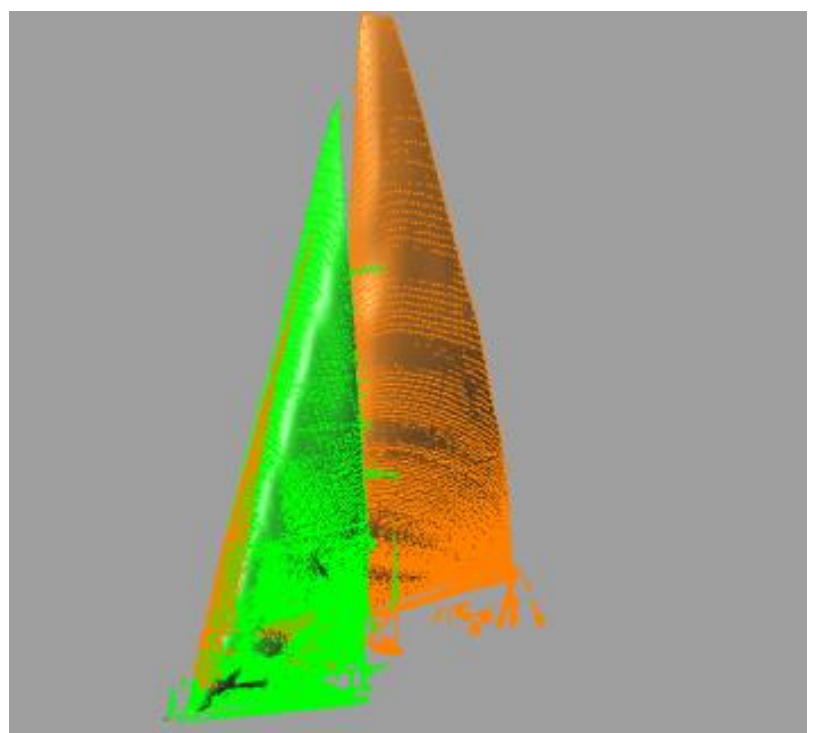

Figure 47 TOF output: sail surface reconstruction from a point cloud

Finally figure 48 shows and example of the comparison between the reconstructed 3D sail shapes superimposed to the SYL CAD model and the correspondent jib picture taken on board in the same conditions (figure 49).

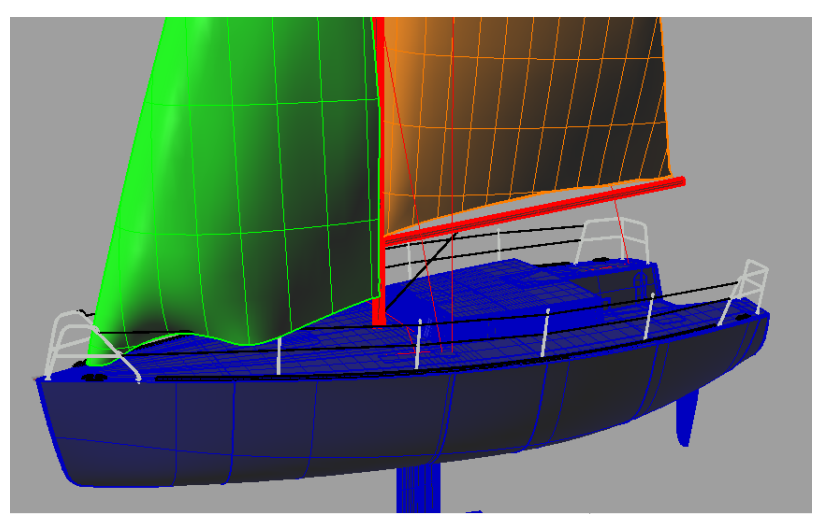

Figure 48 TOF output: reconstructed sails-boat alignment 


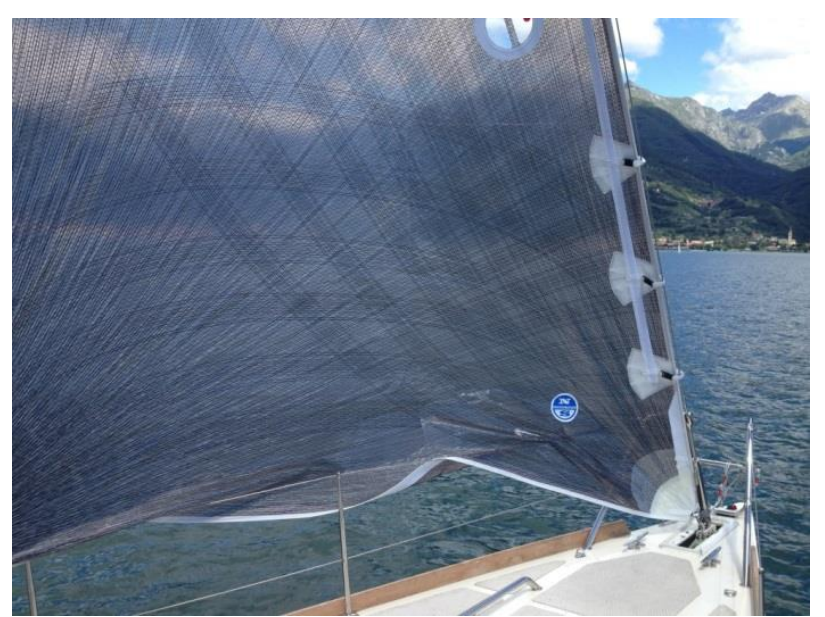

Figure 49: jib picture corresponding to the TOF reconstruction of figures 46, 47, 48.

\section{PERSPECTIVE OF THE POTENTIAL OF SAILING YACHT LAB PROJECT}

Despite the increasing amount of research in yacht engineering field, in authors' opinion there is still a real need for researchers to get together to debate the issues about sail aerodynamics. In particular the correlation between scale model tests and CFD simulations with actual sailing performance remains an interesting topic.

Until now there are few full scale tests for the assessment of hydrodynamic forces of sailing boats.

As mentioned in the introduction the procedure used for the Gimcrack project was based on full scale tests, where apparent wind speed and direction as well as boat speed were measured, and scale model tests where driving force, heeling force and the ratio between heeled and upright resistance were measured. With the data from model tests it was possible to calculate the set of sail coefficients in terms as a function of the heel angle alone.

While Gimcrack was sailed "by an experienced helmsman and measurement were recorded when it was judged that the boat was sailing at optimum speed made good to windward", Sailing Yacht Lab full scale performances can be identified and recorded in quite superior way. The sailing dynamometer allows the direct evaluation of driving and heeling forces and the assessment of the resulting coefficients so that no extrapolation from tank test is necessary.

The resulting coefficients could be used for similar hull forms and sail geometries and will highlight eventual modelship correlation.

This last presents peculiar aspects when dealing with sailing yachts and further contributes based on geosim hulls could led to widely applicable results.

An experimental program based on two scale models (i.e. 1/4 $1 / 8$ scale ratio) of the SYL hullform and on the full scale results could be most interesting for a better evaluation of correlation factors and to highlight viscous resistance breakdown.

Important and precise information about heeled resistance/upright resistance ratio could be obtained. Furthermore full scale hydrodynamic data can be a valuable benchmark for CFD developments.

The possibility to know the true direction of the boat motion and the assessment of aerodynamic force component in such direction allow to evaluate the hydrodynamic resistance considering induced resistance due to leeway angle also.

These aspects has not been considered, till now, by the existing sailing dynamometers that are mainly focused on aerodynamic aspects. Only the Berlin "Sail-Force-Dynamometer" Dyna, [8] deals extensively with hydrodynamics aspects in terms of interaction hull-keel-rudder aimed at appendages optimization.

During sailing test SYL allows longitudinal trim and more in general vertical motions recording; while is common practice to identify pitch and heave during scale model tank tests in rough sea, the behavior of the full scale hull subjected also to aerodynamic forces induced by rig and sails can be analyzed by SYL. This matter is most important and related to key factors affecting sailboat performance as apparent wind modifications, added resistance in waves and pitch damping and its effect on added resistance. Skinner [22] presented the first work where the coupling of aero and hydrodynamics effects was investigated with the aim to predict contribution of aerodynamic damping in total damping. Author concluded that pitch can be reduced by $14 \%$ while roll was over-damped. The problem of added resistance in upright and heeled condition was considered both experimentally on scale models ([23], [24], [25]) and numerically ([26]), but none of sailing Labs reported these results.

Bordogna in [27] presented a time domain program considering 3degrees of freedom strip theory (surge, heave and pitch) where unsteady aerodynamic force due to the boat motions is accounted for. Author discussed on the correct prevision of motions and added resistance due to correct aerodynamic damping calculated according to Fossati and Muggiasca method ([28], [29]). 
Full scale sailing tests in rough water will record full scale data to be used as benchmark for software testing and for better understanding of towing tank and wind tunnel tests.

A dedicated SYL experimental campaign will be focused on seakeeping aspects measuring motions and accelerations.

Vertical motions will be evaluated, at LCG and at bow integrating the accelerations measured through accelerometers. As pointed out by Milgram ([30]), if the results are to be extended for irregular waves, then is of paramount importance knowledge of real sea spectrum. To such extent, the installation of a wave measuring buoy on site during the tests campaign is planned.

Roll damping of sailing boats and roll motion induced by aerodynamic forces in running conditions have received main attention during seventies and eighties ([31] [32]). At present both for increased sail shape control and due to lighter and wider hullforms of much easier steering these matters are less present in the research trends. Nevertheless they represent an important issue both for safety and for performance and the availability of full scale results could encourage again the research on these topics [33].

\section{CONCLUSIONS}

In the present paper an overview of the Lecco Innovation Hub project has been provided with particular reference to the Sailing Yacht Lab project which aims to be a full scale measurement device in the sailing yacht research field.

A description of scientific frame, measurement capabilities as well as of the principal design, building process, project management and committing has been provided.

SYL development is still in progress and the potential of this new available tool in order to deal also with hydrodynamics are suggested.

\section{ACKNOWLEDGEMENTS}

The authors wish to express their gratitude for the support received by Fondazione Cariplo foundation and by Univerlecco which funded $50 \%$ of the overall project.

\section{REFERENCES}

1. Fossati F. et al., 'Wind Tunnel Techniques for Investigation and Optimization of Sailing Yachts Aerodynamics', $2^{\text {nd }}$ High Performance Yacht Design Conference Auckland, 14-16-Feb. 2006

2. Davidson K.S.M., 'Experimental Studies of the sailing yachts', Transaction of SNAME, Vol. 44, 1936

3. Ranzenbach R., Kleene J.: 'Utility of flying shapes in the development of offwind sail design databases', $2^{\text {nd }}$ High performance Yacht Design Conference, Auckland 2002

4. Graf K., Muller O.: 'Photogrammetric Investigation of the flying shape of spinnakers in a twisted flow wind tunnel' Proceedings of the $19^{\text {th }}$ Chesapeake Sailing Yacht Symposium, Annapolis 2009.

5. Renzch H., Graf. K.: 'An experimental validation case for fluid structure-interaction simulations of downwind sails' Proceedings of the $21^{\text {th }}$ Chesapeake Sailing Yacht Symposium, Annapolis 2013.

6. Milgram J.H, Peters D.B., Eckhouse D.N., 'Modelling IACC Forces by Combining Measurements with CFD', $11^{\text {th }}$ Chesapeake Sailing Yacht Symposium, 1993.

7. Masuyama Y., Fukasawa T., 'Full scale measurements of sail forces and the validation of the numerical calculation methods', Proceedings of the 13th Chesapeake Sailing Yacht Symposium, 1997.

8. Hochkirch H., Brandt H. Y., 'Full Hydrodynamic Force Measurements on the Berlin Sailing Dynamometer', Proceedings of the $14^{\text {th }}$ Chesapeake Sailing Yacht Symposium, 1999.

9. Masuyama Y., The work achieved with the sail dynamometer boat "Fujin and the role of full scale tests as the bridge between model tests and CFD", $3^{\text {rd }}$ International Conference on Innovation in High Performance Sailing Yachts, Lorient, France, 2013

10. Hentinen M., Holm G., 'Load Measurements on the $9.4 \mathrm{~m}$ Sailing Yacht SAIL LAB', Proceedings of the $13^{\text {th }}$ International HISWA Symposium on Yacht Design and Construction, 1994.

11. Zseleczky J., Beaver B. "Full Scale Measurements on a Hydrofoil International Moth", Proceedings of the 19th Chesapeake Sailing Yacht Symposium, 2009 
12. Augier, B., Bot, P., Hauville, F., "Experimental full scale study on yacht sails and rig under unsteady sailing conditions and comparison to fluid structure interaction unsteady models". Proceedings of the $20^{\text {th }}$ Chesapeake Sailing Yacht Symposium, 2011

13. Augier, B., Bot, P., Hauville, F., Durand M., "Experimental validation of unsteady models for fluid structure interaction: Application to yacht sails and rig". J. Wind Engng and Ind. Aero. 2012, 101, 53-66

14. Lozej, M., Golob, D., Bokal, D., "Pressure distribution on sail surfaces in real sailing conditions", 4th High Performance Yacht Design Conference, Auckland, pp. 242-251, 2012

15. Viola, I.M., Flay, R.G.J., "Sail Aerodynamics: On-water pressure measurements on a Downwind Sail", Journal of Ship Research, VO1. 56, No 4, Dec 2012 pp.197-206

16. Graves W. et al., "Measurements and simulation of pressure distribution on full size scales", 3rd High Performance Yacht Design Conference, Auckland, 2008

17. Puddu P., et al., "Full scale investigation of one-design class catamaran sails", 2nd High Performance Yacht Design Conference, Auckland, 2006

18. Le Pelley, D., Morris, D., Richards, P., “Aerodynamic force deduction on yacht sails using pressure and shape measurements in real time", in 4th High Performance Yacht Design Conference, Auckland, pp. 28-37, 2012

19. Fossati F., Mainetti G., Malandra M., Sala R., Schito P., Vandone A., 'Offwind Sail Flying Shape Detection', $5^{\text {th }}$ High Performance Yacht Design Conference Auckland, 2015

20. http://www.polimi.it/ricerca-scientifica/brevetti

21. http://www.ricerca.polimi.it/index.php?id=5041

22. Skinner G.T., Sailing Vessel Dynamics, Investigation into Aero-Hydrodynamics Coupling, M.Sc. Thesis, Massachusetts Institute of Technology, June 1982

23. Kapsenberg G.K., A New Techinque for Testing a Sailing Yacht in Waves, Proceedings of $10^{\text {th }}$ Chesapeake Sailing Yacht Symposium, 1990

24. Gerritsma J., Keuning J.A., Onnink R. (1992), Sailing Yacht Performances in Calm Water and in Waves, Report No. 925-P, $12^{\text {th }}$ Int. Symposium on Yacht Design and Construction, HISWA, November 1992

25. Gaillarde G., de Ridder E.J, van Walree F., Keuning J. (2007), Hydrodynamic Advice of Sailing Yacths through Seakeeping Study, The $18^{\text {th }}$ Chesapeake Sailing Yacht Symposium, 2007

26. Jacquin E., Roux Y., Guillerm P., Alessandrini B. (2005), Toward Numerical VPP with the Full Coupling of Hydrodynamic and Aerodynamic Solvers for ACC Yacht, Proc. Of $17^{\text {th }}$ Chesapeake Sailing Yacht Symposium, SNAME

27. Bordogna G. (2012), The Aero-Hydrodynamics Characteristics of Yachts Sailing Upwind in Waves, M.Sc. Thesis, TU Delft, 2012

28. Fossati F., Muggiasca S., Experimental Investigation of Sail Aerodynamic Behaviour in Dynamic Conditions, Journal of Sailboat Technology, Article 2011-02, SNAME

29. Fossati F., Muggiasca S., "Numerical Modelling of Sail aerodynamic behavior in dynamic conditions", $2^{\text {nd }}$ International Conference on Innovation in High Performance Sailing Yachts, Lorient, France, 2010

30. Milgram J.H. (1996), Hydrodynamics in Advanced Sailing Design, $21^{\text {st }}$ Symposium on Naval Hydrodynamics, Trondheim 1996, pp. 635-659

31. Marchaj C. A., (1988) Aero-hydrodynamics of sailing, Adlard Coles Nautical, London

32. Fossati F., (2009) Aero-hydrodynamics and the performance of sailing Yachts, Adlard Coles Nautical, London

33. Klaka K., Krokstad J., Renilson M.R, "Prediction and measurement of the roll motion of a sailing yacht at zero forward speed" 14th Australasian Fluid Mechanics Conference, Adelaide 2001

34. Structural design of a dynamometric sailing yacht. Internal Report, Department of Mechanical Engineering, Politecnico di Milano. 